\title{
The impact of Brexit on International Students' Return Intentions*
}

\author{
Jane Falkingham ${ }^{\dagger} \quad$ Corrado Giulietti ${ }^{\ddagger} \quad$ Jackline Wahba ${ }^{\S}$ \\ Chuhong Wang $\mathbb{1}$ \\ (forthcoming in Manchester School) \\ Accepted version: December 2020
}

\begin{abstract}
This paper studies the causal impact of Brexit on the post-graduation mobility decisions of EU students in the UK. We exploit the British government's formal withdrawal notification under Article 50 as a natural experiment. Using data from a survey of graduating international students administered before and after the triggering of Article 50, we find that EU students are significantly more likely than non-EU students to plan on leaving the UK upon graduation immediately after the announcement. Results are driven by students from the new EU countries and students from the EU14 countries who do not have firm migration plans.
\end{abstract}

JEL Classification: J15, J61

Keywords: Brexit; Article 50; Higher education; International students; Migration intentions.

${ }^{*}$ We would like to thank the Office for National Statistics for funding the first wave of the SoGIS and for their input in conjunction with Universities UK in helping us to conduct the SoGIS survey. The second wave of the SOGIS has been funded by the ESRC under grant ES/K007394/1. We are grateful to the participants of the 2018 British Society for Population Studies Conference for useful suggestions on an earlier draft. Any errors are ours alone.

${ }^{\dagger}$ ESRC Centre for Population Change, University of Southampton, Southampton, SO17 1BJ, United Kingdom. E-mail: J.C.Falkingham@soton.ac.uk.

${ }^{\ddagger}$ Corresponding author. Department of Economics, University of Southampton, Southampton, SO17 1BJ, United Kingdom. E-mail: C.Giulietti@soton.ac.uk.

$\S$ Department of Economics, University of Southampton, Southampton, SO17 1BJ, United Kingdom. Email: J.Wahba@soton.ac.uk.

IYango University, Fuzhou, China. E-mail: flora7819@gmail.com. 


\section{Introduction}

In the past few decades, international migration has been growing worldwide. While many migrants decide to permanently settle in the host country, for many others migration is a temporary process and they eventually return home. Return migration can be a planned decision, in which case it is influenced by, e.g., differences between the home and host country in terms of prices (Galor and Stark, 1991) or in terms of wages and labor market "riskiness" (Dustmann, 1997) and because migrants have preferences for consumption in the home country (Hill, 1987; Djajić and Milbourne, 1988). Temporary migration can also occur because immigrants are unable to fulfil their original plans due to imperfect or erroneous information on the labor market conditions in the host country (Borjas and Bratsberg, 1996). Pinning down the determinants of temporary migration is however an empirical challenge, both because of lack of data and because it is arduous to identify a causal relationship. By exploiting quasi-experimental settings, more recent studies provide credible identification of the host country characteristics that influence return migration. Specifically, these studies look at how exchange rate shocks (Yang, 2006) or exogenous changes in attitudes towards migrants (de Coulon et al., 2016) affect the choice or the intention to return. ${ }^{1}$ To the best of our knowledge, however, no study so far has investigated how unexpected changes in the political and institutional settings of the host country influence temporary migration.

Our paper fills this gap by studying how the UK government's formal notification of its intention to leave the European Union under Article 50 affects settlement intentions among a representative sample of international graduating students. This important policy announcement provides a quasi-natural experiment that generates sizeable exogenous shocks to the post-study migration decision-making of a particular group, namely EU students. We use a difference-in-differences approach whereby we compare migration intentions of EU students with those of non-EU students before and after 29 March 2017 - the day when Article 50 was triggered by the UK government. We consider EU students as our "treatment group" because the UK decision of leaving the European Union is likely to substantially affect their prospects, while it virtually has no effect on international students from other areas, who can

\footnotetext{
${ }^{1}$ See Wahba (2014) for a review on the determinants of return migration.
} 
be used as "control group". Although the outcome of the United Kingdom European Union membership referendum in June 2016 (commonly referred to as the Brexit referendum) was the biggest shock, the triggering of Article 50 is the first legal step and sanctions the commitment by the UK to exit the EU and at the same time sets off the two years "countdown" to the actual exit. Considering that in the months after the referendum there were public pressures and even calls by some political parties for a second referendum, the invoking of Article 50 embodies the most concrete action towards the UK exiting the EU. We postulate that the triggering of Article 50 could affect EU students' post-study return plans through (at least) four channels: 1) an economic channel: EU graduates may be deterred to stay in the UK by higher tuition fees and more uncertain employment opportunities, while more favourable exchange rates might partially offset the negative effects; 2) a legal channel: EU students could face more complex and bureaucratic visa procedures if freedom of movement discontinues, thereby increasing their likelihood to leave the UK; 3) family channel: EU students may be unwilling to stay in the UK after graduation whilst facing uncertainty about their future status and that of their family and 4) a psychological channel: EU students might perceive that the UK is a less welcoming place to study as a reflection of the growing anti-EU sentiment and hate crimes.

Using unique data from the Survey of Graduating International Students (SoGIS) for both undergraduate and postgraduate final year graduating students, we find that immediately after the government's announcement, EU students are about 18 percentage points more likely than non-EU students to plan leaving the UK upon graduation. Importantly, we find heterogeneous treatment effects depending on the nationality and on the degree of certainty about mobility intentions. In particular, while all students from the countries that joined the EU after 2004 seem to be affected by the policy announcement, only EU14 students who do not have firm migration plans appear to be impacted by the policy announcement. Furthermore, there are differences in the magnitude of the effect depending on the age and subject of study.

Besides contributing to the literature on temporary migration, our paper also relates to two other research strands. First, we enrich the growing literature on the determinants of international student mobility (Rosenzweig et al., 2006; González et al., 2011; Beine et al., 
2014; Haupt et al., 2016; Bijwaard and Wang, 2016; Bahna, 2018). Second, we contribute to the recent literature on the effects of Brexit (NIESR, 2016; OECD, 2016; Dhingra et al., 2016a,b, 2017; Wadsworth et al., 2016)

The remainder of the paper is structured as follows. Section 2 briefly introduces the background of the study and the possible channels through which Brexit could affect student mobility intentions. Section 3 illustrates the empirical strategy used to identify the causal effect and discusses potential threats to identification. Section 4 describes the data. The main results as well as a number of robustness tests are presented in Section 5, while Section 6 concludes.

\section{Background and Theoretical Framework}

International student mobility has been rising globally over the past few decades and is an active policy area. In 2017, there were 134,835 international students in the UK, $30 \%$ of which from the European Union (HESA, 2017). ${ }^{2}$ International students bring unique talent and skills, contribute to a diverse academic environment, ensure the provision of subjects, and generate economic benefits through their consumption. They also constitute a potential pool of skilled labour market entrants, especially in the case of EU students, who have virtually no restrictions for working in the UK. While this might raise concerns about potential competition between foreign and native graduates, evidence for the UK shows that immigration does not adversely impact UK-born workers (Manacorda et al., 2012).

How can the decision to leave the EU affect UK international students' return decisions? Even before Brexit produces actual changes in migration laws, policy announcements such as the triggering of Article 50 can influence - directly or indirectly - the decision to stay or migrate out of the UK through a multitude of economic, legal and psychological factors. In particular, it could influence student expectations in terms of university fees, funding opportunities, labour market perspectives, visa requirements, prices and exchange rates, and more generally, the social and cultural climate.

\footnotetext{
${ }^{2}$ Throughout the paper the term EU means European Union excluding the UK, and therefore EU students refer to non-UK EU students.
} 
From an economic perspective, students migrate to enhance their human capital so to obtain higher wages upon return, or to gain access to better economic opportunities in the host country (Rosenzweig et al., 2006; Dustmann et al., 2011). In a study based on the Netherlands, Bijwaard and Wang (2016) find that foreign students return faster once they become unemployed. While there is still no clearcut evidence on whether Brexit creates negative economic consequences, the result of the referendum, and the triggering of Article 50 have both contributed to more insecure economic conditions, potentially worsening job/educational prospects for international students and therefore making them less inclined to stay. For example, international students currently enrolled in undergraduate programs in the UK might want to pursue their post-graduate investment in a different country, to the extent that direct costs of British higher education increase. This is true especially for EU students, who are currently charged the same fees as the UK-born students, but might be exposed the higher overseas rates and face restrictions to student loans and EU scholarships once the UK leaves the European Union. Likewise, students who intend to remain in the UK and work after graduation might feel less confident about their future career prospects and earning capacity because of a weaker post-Brexit UK economy. On the other hand, international students could benefit from the weakening of the Pound which followed the referendum vote and, if persistent, can make the UK a cheaper place to study and live. This will particularly benefit students who plan to continue studying in the UK, whilst deterring those who desire to remain for work-related reasons. ${ }^{3}$

Another channel through which Brexit can affect return intentions of (especially EU) students is through the expected changes to the UK immigration law regarding free movement of people between the EU and UK. European and EEA/Swiss national students currently hold a legitimate expectation that they will be able to remain legally for as long as they wish. However, after Brexit there will be added bureaucratic burdens on these students regardless of the new immigration system adopted, given that the British government will likely toughen the immigration policy and incorporate international students within the overall immigration targets. In the scenario where the UK withdraws from existing agreements on

\footnotetext{
${ }^{3}$ The devaluation in the Pound makes UK jobs less attractive for foreign workers, who hope to earn higher wages abroad and then remit money to their home country.
} 
freedom of movement, EU students will need to apply for a visa in order to study or work in the UK, which is obviously onerous and expensive. Moreover, there will be a prolonged period of uncertainty over the future residency/citizenship rights and status of EU nationals. As argued by Portes (2016), if people "cannot plan with any confidence, not just about themselves but their families, they are less likely to come and less likely to stay." It is thus reasonable to expect that the legal effect of Brexit through potential visa burdens might act as a strong disincentive for EU graduates to stay in the UK.

Finally, the Brexit vote per se may have a direct psychological impact on EU student leave intentions, relating not only to the distress and anxiety caused by inherent uncertainties around the UK leaving the EU, but also the perception of an increasingly hostile environment for EU citizens. As showed in Hazen and Alberts (2006), feelings of alienation from a foreign culture are recognised as the most common reason why international students return. Indeed, in the wake of the referendum vote there was a surge in hate crimes along with unpleasant xenophobic episodes against EU residents. ${ }^{4}$

In summary, increases in educational and legal costs, reduced economic confidence and perceived hostility are likely to discourage EU students to stay, unless the positive gains from more favourable exchange rates are able to more than compensate the negative Brexit effect.

\section{Methodology}

We exploit the triggering of Article 50 as a quasi-experiment that generates exogenous variation in the post-graduation out-migration intentions of foreign students. ${ }^{5}$ By officially launching the Brexit process, this "shock" changes the expectations of EU students over their future rights and status in the UK, therefore affecting their intentions to stay. We postulate that this effect is particularly for students who are uncertain about their intended plans after graduation. International students who are non-EU nationals serve as a natural

\footnotetext{
${ }^{4}$ https://assets.publishing. service.gov.uk/government/uploads/system/uploads/attachment_ $\mathrm{data} / \mathrm{file}$ /543679/Action_Against_Hate_-_UK_Government_s_Plan_to_Tackle_Hate_Crime_2016. pdf.

${ }^{5}$ Article 50 was invoked with a notification letter to the European Council. Details about Article 50 are reported in Section A in the Appendix.
} 
control group since they are (completely or greatly) unaffected by the exit of the UK from the EU. The key reason why non-EU students are unlikely to be affected by the triggering of Article 50 is that or the large majority of them, the amount of time that they can remain in the UK is predetermined by the duration of their student visa. In other words, non-EU students would have to leave the UK irrespective of the triggering of Article 50. ${ }^{6}$ Exploiting a unique survey of international students in the UK which spans the period before and after the invoking of Article 50, we employ a difference-in-differences (DID) design comparing the intentions to leave of EU students with the intentions to leave of non-EU students, before and after 29 March 2017 - the day when Article 50 was triggered by the UK government.

We implement the difference-in-differences estimation within a regression framework and include several covariates to better control for characteristics that might be systematically different between the treatment and control group. The DID regression model takes the following form:

$$
I T L_{i t}=\beta_{0}+\beta_{1} E U_{i}+\beta_{2} \text { Post }_{t}+\beta_{3} E U_{i} \times \text { Post }_{t}+\mathbf{X}_{i t}^{\prime} \gamma+\lambda_{s}+\lambda_{u}+\varepsilon_{i t}
$$

where the dependent variable, $I T L_{i t}$, is the intention to leave the UK after graduation for student $i$ at time period $t$; $E U_{i}$ is a dummy indicating whether the student is a citizen of the $\mathrm{EU}$ and 0 otherwise, with the coefficient $\beta_{1}$ capturing all possible systematic differences between students from EU and non-EU countries; Post $t_{t}$ is a dummy that is equal to one for all interview days after the declaration date (i.e., from 30 March 2017 onwards), and zero otherwise. This indicator controls for differences in students' mobility intentions over time that might be due to macroeconomic changes that affect both groups or simply to "calendar effects". The interaction term $E U_{i} \times$ Post $_{t}$ identifies the EU students who were exposed to the Article 50 news. The key coefficient is $\beta_{3}$, which measures the average treatment effect. A positive estimate of $\beta_{3}$ would imply that the Article 50 announcement increased EU students' leaving intentions. $\mathbf{X}_{i t}$ is a vector of students' characteristics such as age, gender, marital status, labour market engagement, duration of stay in the UK, level of study

\footnotetext{
${ }^{6}$ Indeed, Brexit - to the extent that it could alter the UK's attractiveness as a place to study and live - might, in the future, influence migration plans for perspective non-EU students. Since the focus of our analysis is on current students, however, this will not affect our identification strategy.
} 
and health conditions. ${ }^{7}$ We also include dummies to account for systematic differences in terms of subject of study $\left(\lambda_{s}\right)$ and universities $\left(\lambda_{u}\right)$. In all regressions, we cluster standard errors at the university level to account for the possibility that observations are correlated within the same institution. ${ }^{8}$ We first estimate Equation 1 for the sample of all students, and then on a particular subset of students, namely those who are uncertain of their plans after study. Importantly, we also corroborate that being uncertain is not itself an outcome of the Article 50 news, therefore ruling out the presence of selection bias. We do so by estimating Equation 1 where the dependent variable is a dummy indicator for whether the student is uncertain about their return plans, and showing that the relevant coefficients are statistically insignificant.

The DID strategy allows a comparison of average leave intentions over time for EU students, whilst controlling for concurrent time trends by using the non-EU as a control group. A further advantage of this approach is that it effectively eliminates the bias when selection into treatment is based on time invariant unobservable characteristics (that are also correlated with the outcome measures). For instance, if EU students are a selected group that is intrinsically more motivated and risk-taking than non-EU students and hence has a higher intention of staying anyway, any potentially adverse treatment effects of the Article 50 announcement on migration intentions would be downward biased. By calculating the differences twice, such time invariant individual heterogeneity (i.e., motivation and risk attitudes) will be differenced out.

The key identifying assumption of the DID approach is that - in absence of the treatment - return intentions of EU and non-EU students would follow parallel trends over time. In other words, the non-EU group is a credible counterfactual to the extent that it "mimics" how migration intentions for EU students would have changed had they not been exposed to the Article 50 news. We test the plausibility of this assumption in Section 5. It is worthwhile to mention that the chance of violating the parallel trend assumption is slender given the rather

\footnotetext{
${ }^{7}$ Health status is self-reported. The variable we use in our analysis is based on the Question 28 of SoGIS which asks: "How is your health in general? Would you say it is...1) Very good, 2) good, 3) fair, 4) bad, 5) very bad."

${ }^{8}$ In unreported regressions, we test the robustness of our results against different clustering scenarios. Specifically, we re-estimate our specifications clustering the standard errors at the individual level, at the subject level, and at the university $\times$ subject level. We find that these alternative ways of accounting for dependence in error terms yield very similar results to clustering at the university level.
} 
narrow time range of our data. This is because students interviewed just before and after the notification date were exposed to similar economic conditions and face almost identical rules and regulations that directly impact upon their post-study movement, such as tuition fees policy, working rights and acquisition of British citizenship.

Another important identifying assumption is that students could not self-select into treatment or comparison group. In our DID setting, a student's exposure to the treatment is determined jointly by two variables: their nationality and the date of participation in the survey. There are thus two types of selection bias that are of potential concern: selection across group and across time. Our - plausible - assumption is that students could not manipulate their nationality and that they should not choose the date of interview based on expected gains or losses from the policy announcement. It seems highly unlikely that anticipation about the declaration of the Article 50 letter would induce students to shift the timing of interview to an earlier or a later date. Instead, the choice of dates is more likely to hinge on when they received the survey invitation or the reminder to complete the survey. Thus, the dates on which students answered the survey before or after the UK government's official notice can be thought to be random. In addition, although the exact date of notification was well anticipated to be by the end of March 2017, it is both rationally and administratively infeasible for students to change nationality with the expectations of detailed terms in the notification letter. Therefore, an individual's nationality can be regarded as fixed over this short sample window and we expect no systematic self-selection of certain types of students across the news date. Nonetheless, in our additional tests, we still corroborate the absence of such self-selection.

In robustness checks, we refine our identification strategy in two ways. Firstly, we improve upon the basic difference-in-differences model by performing a difference-in-differences in conjunction with a weighting procedure. The implementation of this estimation strategy consists of two steps. In the first step, we re-weight control group observations via propensity score methods or entropy balancing, to ensure the comparability of treatment and control groups with respect to a set of conditioning variables. ${ }^{9}$ In terms of propensity score

\footnotetext{
${ }^{9}$ The conditioning variables are selected following the control variables used in our study, including the demographic, labour market, educational and health data of international students - except for the variables of universities that we replaced with a dummy for being a member of the Russell Group to improve the
} 
weighting, we match the covariate distributions of the treatment and control group within periods by assigning a weight that equals $P(\mathbf{X}) /(1-P(\mathbf{X}))$ to the untreated students, with propensity score weights estimated separately at each time period. ${ }^{10}$ In the second step, we perform difference-in-differences regressions comparing the change in intentions to leave between observationally equivalent EU and non-EU students, with the sampling weights obtained from the first step. The DID part of the estimator reduces selection bias stemming from time-invariant unobserved heterogeneity between treated and untreated students (such as unobserved motivation and attitudes towards risk), while the re-weighting part of the estimator will deal with bias due to self-selection on observables.

Secondly, rather than stratifying the sample by students' level of certainty over future plans, we again focus on the full sample but use decisive students as an additional control group. This corresponds to a difference-in-difference-in-differences (DDD) setup that exploits more variation in data and applies higher-order contrasts to draw causal inferences. Specifically, we not only rely on differences in outcome pre- and post- the triggering of Article 50 but also on the comparison of EU and non-EU students who are equally uncertain about their intentions and the same group with different degrees of certainty about their intentions. Accordingly, we estimate the following regression:

$$
\begin{aligned}
\text { ITL }_{i t} & =\alpha_{0}+\alpha_{1} \text { EU }_{i}+\alpha_{2} \text { Post }_{t}+\alpha_{3} \text { Uncertain }_{i}+\alpha_{4} \text { EU }_{i} \times \text { Post }_{t}+\alpha_{5} \text { Post }_{t} \times \text { Uncertain }_{i} \\
& +\alpha_{6} E U_{i} \times \text { Uncertain }_{i}+\alpha_{7} \text { EU }_{i} \times \text { Post }_{t} \times \text { Uncertain }_{i}+\mathbf{X}_{i t}^{\prime} \gamma+\lambda_{s}+\lambda_{u}+\varepsilon_{i t}
\end{aligned}
$$

where Uncertain $_{i}$ is a dummy indicating whether the students are uncertain or not about their mobility plans after university. In this model, the key parameter of interest to identify is $\alpha_{7}$. The inclusion of lower-level interaction terms enables us to control for more potential sources of omitted variable bias. In particular, any time varying selection bias - say efficiency of matching.

${ }^{10}$ Entropy balancing is a data-preprocessing method that can more effectively achieve covariate balance than conventional adjustment methods (Hainmueller, 2012). It calculates the covariate moments in the treatment group and searches for a set of weights that satisfy pre-specified balance constraints imposed on the sample moments to assign to control group observations. In this paper, we equalise the first two moments (mean and variance) of the covariate distributions across the treatment and the re-weighted control group. We impose entropy balancing separately for the pre- and post-period to obtain two weights $W_{E B}^{\text {pre }}(\mathbf{X})$ and $W_{E B}^{\text {post }}(\mathbf{X})$. 
changes in group composition over time as we previously mentioned, will no longer hinder the causal interpretation of the estimates, provided that self-selection patterns are constant across decisive and uncertain students. Another important benefit of this research design is that it arguably relies on weaker identifying assumption than parallel trends. ${ }^{11}$ Therefore, triple differences may allow for a more robust and credible analysis of the causal impact of the policy announcement on student mobility intentions.

\section{Data}

\subsection{Description}

We draw data from the Survey of Graduating International Students (SoGIS), conducted jointly by the ESRC Centre for Population Change, the Office for National Statistics and Universities UK. A technical description of the SoGIS dataset is provided by Falkingham et al. (2017). This is an online survey targeting international (non-UK) students in their final year of study at UK higher education institutions (HEIs). The first wave was conducted between March and April 2017 and a follow-up survey took between December 2017 and February 2018. Our main analysis is based on the first wave of the survey. The SoGIS 2017 collected information from 3,560 students from more than 130 countries across 51 participating HEIs. The overall response rate to the survey was 3.5\%. We have verified the representativeness of our survey by comparing key characteristics of the students in our sample with statistics from the UK Higher Education Statistics Agency (HESA). For example, the shares of EU students in our sample (28.7\%) is slightly higher than the full international population of UK international finalists (22.3\%). Also, in our survey, postgraduate students represent $67 \%$ of the sample, while according to HESA data, this group represents only $45.5 \%$ of all finalists. This implies that our data are somewhat over-representing EU students and students in postgraduate programmes - and thus our inference needs to take this into account. In this exercise, we also compare the trends in international students' enrolment for all UK Higher Education Institutions (HEIs) institutions with the subset participating in

\footnotetext{
${ }^{11}$ It simply requires the absence of contemporaneous shocks that disproportionately influence EU students who are unsure of their post-study mobility intentions between the pre- and post-notification period.
} 
our survey, finding that the patterns are very similar, and further reassuring us about the representativeness of participating HEIs. Further details about the representativeness of our survey are outlined in Falkingham et al. (2017). ${ }^{12}$

The SoGIS is well-suited for our purposes for several reasons. First, one key benefit of this dataset is that the survey sample is representative of the overall international student population in the UK (albeit it over-represents postgraduate students). Furthermore, the participating universities are also representative of all UK HEIs. Second, the data contain detailed information about the international students' background, post-study intentions, certainty of these intentions, travel patterns, use of public services, and working patterns whilst studying. The availability of the "intentions" data is particularly valuable for investigating questions concerning international student mobility. Third, the data span a period before and after 29 March 2017, which gives us the opportunity to exploit the timing of the Article 50 letter.

We measure international students' post-graduation migration intentions using answers to the question "After finishing your current course of study, how long are you planning to stay in the UK?". Respondents are given the following options: 1. Leave immediately; 2. Less than three months; 3. Three months or more but less than six months; 4.Six months or more but less than twelve months; 5 . Twelve months or more; 6. I intend to stay and qualify for permanent residence if possible. The subsequent question asks about the degree of certainty that the students have about their settlement plans. ${ }^{13}$ Figure 1 shows the corresponding distribution of staying intentions for EU and non-EU students. On average, EU students report stronger preferences to stay. Non-EU students are more likely to report that they will leave the UK immediately or stay for less than 6 months, whereas EU students are more likely to say that they are planning to stay in the UK for longer than a year or

\footnotetext{
${ }^{12}$ There is no evidence that relative response rates have been affected by the treatment (e.g., that students in the treatment or control group are more or less likely to respond to the survey as a consequence of invoking Article 50). To show this, we have estimated a model where we regress the number of daily responses on a variable representing the date and on the EU indicator, the Post dummy and the interaction $\mathrm{EU} \times$ Post. The interaction term is insignificant, showing that the relative response rate between groups is constant after the treatment.

${ }^{13}$ The exact wording of this question is as follows: "How certain are you about how long you are staying in the UK?". The possible answers are: 1. Not certain at all; 2. Uncertain; 3. Neither certain nor uncertain; 4. Certain; 5. Very certain.
} 
permanently. We exploit this information to construct an indicator for whether the student intends to leave the UK within 3 months after graduating.

\section{[Insert Figure 1 here]}

Figure 2 shows that about one quarter of international finalist students feel unsure of their plans after university. Both EU and non-EU students have fairly similar patterns regarding the certainty of their future plans. Nearly 55 per cent of students are sure of their post-study migration intentions while 27 per cent are irresolute in these intentions (a further 18 per cent report neutral values). We define the group that have not clear migration plans as "Uncertain Students". By focusing on this subgroup we are able to identify students who would have not changed their migration choices without being exposed to the Article 50 news but changed their mind when the letter was announced.

$$
\text { [Insert Figure } 2 \text { here] }
$$

\subsection{Descriptive statistics}

We report summary statistics of key variables separately for the full sample (Table 1) and for the subsample of uncertain students (Table 2).

It is evident that EU students differ systematically in their observable characteristics from non-EU students. The former group is younger and has longer duration of stay in the UK. They are also more likely to be single and to work alongside their studies, and far less likely to study at postgraduate level and at a Russell Group university. ${ }^{14}$ In terms of subject areas, non-EU students are more represented in certain disciplines, such as in engineering and technology and in social sciences and education, while a larger proportion of students choosing arts and humanities are from European countries. The before-after comparison within groups suggests that the composition of the two groups is generally similar - the

\footnotetext{
${ }^{14}$ The Russell Group is formed by 24 public research institutions, namely the Universities of Birmingham, Bristol, Cambridge, Cardiff, Durham, Edinburgh, Exeter, Glasgow, Leeds, Liverpool, Manchester, Newcastle, Nottingham, Oxford, Queen Mary London, Sheffield, Southampton, Warwick, York and Imperial College London, King's College London, London School of Economics, Queen's University Belfast and University College London. The SoGIS covers 13 Russell Group universities.
} 
exception being some differences across universities. Nevertheless, our identification strategy will address this issue by re-weighting the sample to ensure group comparability. Students from the EU have a substantially lower intention of leaving the UK upon course completion than those from outside the $\mathrm{EU}$ (45.0\% versus $62.5 \%$ ). More importantly, the intention to leave after the Article 50 news increases by 0.08 in the treatment group (significantly different at 5 percent level of significance) and only by 0.02 in the control group, corresponding to a raw difference-in-differences of 0.06 .

\section{[Insert Table 1 here]}

Table 2 replicates Table 1 for the 818 observations of international students in our preferred sample of uncertain students, 28 per cent of whom are from EU countries. The differences between EU and non-EU students based on this subsample strongly resemble the treatment-control differences based on the full sample, with respect to student and school characteristics. However, the gaps in leaving intentions are even more pronounced for uncertain students, indicating that the unconditional difference-in-differences of the effect is 18 percent.

\section{[Insert Table 2 here]}

Table B.2 and Table B.3 in the Appendix show the summary statistics of the control variables, i.e., $\mathbf{X}$ in Eq. 1, for the treatment group and for the unweighted and re-weighted control group comparing the results from the propensity score weighting (column 3) and from entropy balancing (column 4). Clearly, the tables show that entropy balancing outperforms propensity score weighting in terms of improving covariate balance. After performing entropy balancing, the treatment-control differences in means are not significantly different from zero for all covariates. In fact, we implement entropy balancing not only for the means but also for the variances (unreported) of the conditioning variables. In particular, it is important to note, as seen in Table B.2, that the share of uncertain students is almost the same in the treatment and control group, which provides us further underpinning to our DDD specification. 


\section{Results}

\subsection{Baseline Regression}

As initial analysis, we provide a graphical representation of the DID method by comparing post-study mobility intentions of treated and control students before and after treatment. The upper panel of Figure 3 plots the average intentions to leave for the entire group of EU students (solid line) and non-EU students (dash line) with the news cut-off date of 29 March indicated by the red line. For EU students, there is a decline in leaving intentions before 29 March, which later reverses and gradually converges to those of non-EU students towards the end of the sample period. Nonetheless, we see that the departure intentions for this group do not differ substantially between the pre- and post-treatment periods. In fact, at the end of April the probability of leaving for EU students is still lower than for non-EU students. Crucially, over the same time period, return intentions remain remarkably constant for non-EU students, suggesting that the control group is unaffected by Article 50 news exposure. These patterns point to small deterrent effect of the withdrawal notice for all EU students.

The lower panel of Figure 3 documents the evolution of leaving intentions for international students who feel who are uncertain about their migration intentions after university. Notably, we observe a different pattern for this subgroup. Before 29 March, EU students with indefinite migration plans have relatively lower intentions to leave the UK after graduation. After 29 March, however, the propensity to leave jumps sharply for this group and is eventually above the values for non-EU students with indefinite migration plans. Despite the probability of leaving after study exhibits some fluctuations across time for uncertain non-EU students, it does not change dramatically after the cut-off date. This confirms the appropriateness of using non-EU students as a comparison group in the estimation of the announcement effect on EU students.

Overall, the graphs in Figure 3 provide strong visual evidence that the triggering of Article 50 may induce EU students, especially those who are still uncertain about their mobility choices, to leave the UK when their study period ends. 


\section{[Insert Figure 3 here]}

Table 3 presents results from the difference-in-differences regression analysis. The specification reported in columns (1) and (4) reports the raw DID estimates (i.e., without any control variables), while columns (2) and (5) show the results after controlling for student background variables, to account for possible changes in sample composition over time. Our preferred specifications are columns (3) and (6), where we additionally control for unobservable factors related to subject and university.

Overall, the estimates confirm the pattern seen in the descriptive analysis, but a stronger inference emerges especially from the specifications with full controls. The significant coefficients for the EU dummy confirm a lower likelihood of leaving the UK upon course completion than non-EU graduates. The coefficients for the Post variable are negligible in magnitude and never statistically significant, implying that there are no macroeconomic shocks that are commonly experienced by EU and non-EU students from the pre- to post-treatment period. This seems reasonable given that the estimation window covers only 49 days. The coefficient estimates of additional covariates also reveal interesting correlations. ${ }^{15}$

Let us now focus on the treatment effect of the Article 50 notice. The first three columns in Table 3 display the results from the full sample of international students. Without control variables (column 1), the estimated coefficient of the interaction term is 0.061 , but with a standard error of 0.046 the estimate cannot be said to be statistically different from zero. A similar result is obtained when we add control variables. When we include fixed effects, the estimate is significant at the $5 \%$ level. This positive, but small and statistically weak effect corroborates the graphical impression of a negligible impact of the Article 50 announcement on the full sample of students.

Estimates from the sample of uncertain students in columns (4)-(6) provide sharper inference. Throughout, the coefficients on the difference-in-differences interaction are strictly

\footnotetext{
${ }^{15}$ For instance, having a job, being an undergraduate, or being a postgraduate significantly reduces intentions to leave, whereas age appears to make no difference. In line with Bijwaard and Wang (2016), gender is not found to affect the departure intentions of international students. Approximately half of students in our sample are in excellent health condition, and we find that healthy students are less likely to leave after graduation, an effect that only exists in the full sample and disappears when we look at the subsample. Not surprisingly, the longer the students are in the UK, the lower the propensity to leave.
} 
positive and statistically significant, suggesting that EU graduates who are irresolute concerning their migration decisions are more prone to leave the UK upon graduation relative to their non-EU counterparts after the UK began the Brexit process. Furthermore, the magnitudes of the estimates are substantially greater compared with columns (1)-(3), so that the announcement increases the intention to leave between 16.2 and 18.4 percentage points. These are very sizeable effects because the average student in this subsample has a 43 percent chance of leaving. Adding the standard set of controls for student background hardly changes the results and estimate remain significant at the 5 percent level of confidence. The DID estimated effect becomes more statistically significant when we include fixed effects.

\section{[Insert Table 3 here]}

One might wonder whether being uncertain or not is itself an outcome of the triggering of Article 50 or instead can be deemed to be a fixed trait of students. In the first case, splitting students along an outcome would cause the estimates to suffer from selection bias. In Table 4 we provide some evidence to rule out that self-selection into being uncertain is an issue. We estimate a regression model along the lines of that in Table 3, using the indicator for being uncertain as the dependent variable. If the Article 50 would trigger a change in the level of uncertainty of EU students, one would expect the interaction term $E U \times$ Post to be economically and statistically significant. The results in Table 4 reveal that this is not the case, suggesting that students' decisiveness is a fixed trait (at least in the short period of time we analyse). ${ }^{16}$

\section{[Insert Table 4 here]}

For completeness, in Table B.1 we repeat the same analysis for the sample of students who are sure of their post-study migration choices. A comparison of the outcome mean reveals that students who are decided about their migration plans are essentially more likely than uncertain students to plan to leave after study (0.63 vs. 0.43). More importantly

\footnotetext{
${ }^{16}$ The full regression results (that we do not report for reasons of space) show that the only variables that significantly correlate with being uncertain are marital and work status, and the university where the students are enrolled, which again capture fixed traits of students.
} 
though, the coefficient estimates of the treatment effect are economically and statistically undistinguishable from zero, indicating no causal impact of the Article 50 notification on student mobility intentions. Therefore, we conclude that the policy announcement does not influence the intentions of students who have already made up their mind about where they will settle or live after graduation.

Taken together, there is strong evidence for a post-treatment increase on the leaving decisions of uncertain EU students as compared to uncertain non-EU students, whereas EU students who are already sure about their migration plans are essentially unaffected by the Article 500 announcement. As a result, the absence of a treatment effect for the whole student population masks the existence of a large deterrent effect for uncertain students and a zero effect for students who are sure about their migration plans. An implication of this is that we could use the latter group (the "decisive" students) as an alternative comparison group - a point we will return to later.

\subsection{Robustness checks}

In this subsection, we first we test the validity of the main assumptions behind the differencein-differences estimation strategy, and then we conduct several checks to corroborate the robustness of our results.

We check the plausibility of the parallel trend assumption in the context of the graphs presented in Figure 3 and of the regression estimates presented in Table 5. The graphs reveal no apparent pre-treatment trends in the outcome between treated and control students, despite such graphical evidence is less clear in the full sample than in the subsample of uncertain students. Although there is a slight decline in the intention to leave during the period preceding the announcement, this drop also occurs in the control group in the subsample, implying that selection into treatment evolves similarly in both groups within the narrow sample window. ${ }^{17}$

\footnotetext{
${ }^{17}$ To further support the evidence that pre-treatment trends are similar for EU and non-EU students, we have estimated a model where we regress intentions to leave for the period before the treatment (i.e., Post $=0$ ) and interact the EU indicator with a continuous variable representing the interview day. In the regression we include the full set of control variables as in Table 3 . The estimate of the interaction coefficient is -0.0126 (s.e. 0.009), suggesting that there is no evidence that, before invoking Article 50, intentions to leave are systematically different between EU and non-EU students.
} 
Table 5 presents the regression results of two placebo analyses using our original DID strategy based on both the complete sample and the sample of uncertain students. In the first test, we restrict the estimation window to the pre-treatment period, i.e., between 13 March 2017 and 28 March 2017. We then define a "pseudo" Post dummy variable as if the Article 50 announcement was made on 19 March 2017 (ten days before the actual date of notification and roughly mid way of the subsample time window). We then create a treatment variable which is the interaction between the "pseudo" Post $t_{t}$ and the EU dummy variable. In the second test, we replace the dependent variable with a "fictitious" intention outcome that is not likely to be affected by the news, namely a dichotomous indicator for whether the student decides to participate in the survey prize draw. If the assumption of parallel trends holds, we should expect the coefficients for the placebo treatment variables to be statistically insignificant in these two specifications. Reassuringly, we see that none of the DID coefficients are significantly different from zero at conventional levels. Hence, overall, but especially regarding the subsample of uncertain students, the falsification tests corroborate that our results are not spuriously driven by pre-treatment differences between EU and non-EU students and can indeed be interpreted as the causal impact of the Article 50 notification.

\section{[Insert Table 5 here]}

In the second set of robustness checks, we examine whether the estimated effects are robust to re-weighting the sample to increase similarity between the treatment and control groups. Table 6 presents the weighted DID estimates adjusted by propensity score techniques (columns 2) and by entropy balancing (column 3). We also control for all conditioning variables used in the balancing procedure. The specifications in columns (2) and (3) differ in the construction of the weights, as detailed earlier. Note that one implied assumption behind the DID approach is that the composition of the treatment group and the comparison group remains constant over time. Importantly, by applying the weighting method in the context of DID models, we are able to control for confounding factors stemming from changes in group composition over time. This assumption is supported by the balancing tests in Table B.2 and Table B.3. The results after refining the identification strategy, presented in Table 6, are 
remarkably similar to those of the main specification. With regards to all students (Panel A), we consistently find positive effects of exposure to the Article 50 news on intentions to leave regardless of the re-weighting procedure used, indicating that EU students are significantly more likely than non-EU students to plan to leave upon graduation as a result of the formal notification of Article 50. When we consider uncertain students (Panel B), the estimates from the weighted DID regressions in the reweighted sample tend to be statistically weaker than in the sample without reweighting, but remain within reasonable range to the benchmark (unweighted) coefficients in terms of the effect size.

\section{[Insert Table 6 here]}

In the third robustness check we use the decisive student sample as an alternative comparison group that has much more similar characteristics and outcomes as the treated group but is unaffected by the government notification. The resulting triple differences estimates are presented in Table 7 . It is important to note that the coefficient estimates on the second order term $E U \times$ Post now become rather small and are insignificantly different from zero, indicating the absence of any temporal shock that differentially affects EU students between the pre- and post-notification period (except for the notification itself). This lends great confidence to the validity of the common trend assumption. Consistent with previous findings, the rise in intentions to leave for EU students that occurs after the government triggered Article 50 is concentrated among students who have not yet made their decision of where to settle after graduating. The relevant point estimate of 0.168 from our preferred DDD specification is remarkably similar to the DD estimate in Table 7 for the group of uncertain, albeit it is estimated with slightly less precision.

\section{[Insert Table 7 here]}

The fact that three alternative sets of DID estimates and DDD estimates yield qualitatively similar results is very reassuring, given the possibility that the benchmark DID estimates could be biased due to the Article 50 news-induced changes in group composition and group-specific shocks other than the treatment. 
In the last robustness check presented in Table 8 we exclude from the estimation sample students who were interviewed on the date of letter announcement. The concern is that, depending on the precise timing of the interview, some students are "treated" while some are not on the cut-off date. Excluding students at the time of notification guarantees that all pre-A50 observations are not exposed to the Article 50 news and all post-A50 observations are exposed to the news. We find that the exclusion of these students makes the estimated effects for the overall sample insignificant but yields remarkably similar estimates for the uncertain subsample.

\section{[Insert Table 8 here]}

\subsection{Heterogeneity}

So far, we have determined that the UK's Article 50 notification has a significant positive impact on the likelihood that EU students will leave the UK after graduating. In the following, we investigate heterogeneity in treatment effects along several important dimensions, including country of origin, age, fields of study, whether the student receives scholarships or loans for their studies, student expectations about final grade, and whether the university at which the student studies is a member of the Russell Group.

\subsubsection{EU nationality groups}

International students from different countries of origin greatly differ in terms of their ties to the home country and integration in the UK. Recall also that Brexit may breed "discrimination" and "hostility" against EU citizens. In particular, there is anecdotal evidence that migrants from countries that have more recently become part of the EU suffer more in this aspect than migrants from the EU14 (i.e., the EU15 excluding the UK). For these reasons, the effect of the Article 50 notification letter on the outcomes of EU students may vary depending on the nationality of the EU student. ${ }^{18}$ To examine whether there is an heterogenous effect, we repeat the DID and DDD analyses replacing the treatment group with two

\footnotetext{
${ }^{18}$ Moreh et al. (2014) use pre-EU referendum data to illustrate that there is great variation within EU migrants in the UK in terms of their coping strategies in the event of Brexit.
} 
EU nationality groups, the EU14 and the "new EU" (i.e., member states that joined the EU after 2004). The comparison group comprises students from outside the EU as before. The results should be therefore informative about the potential heterogenous treatment effects among different affected groups.

In our sample about 22 per cent of all international students come from the EU14 countries and a further 7.2 per cent are from the new EU member states. In Table 9 we report the DID and DDD estimated announcement effects under three different treatment groups (displayed in Panel A, B and C, respectively). In each case the odd columns contain the results without control variables, while the even columns present results after including the full set of control variables and fixed effects. Panel A of Table 9 presents the results based on the original treatment group for comparison purposes. In the complete sample, we find a substantial effect of the Article 50 news on students from the new Member States. The estimated coefficients for the difference-in-differences term, presented in columns (1)-(2) of Panel B, imply an approximately 15 percentage point increase in the probability of leaving after study for this group (significant at the 1 percent level). As can be seen from columns (1)-(2) of Panel C, the respective DID estimates are, however, not significant for all students from EU14 countries.

We next turn to the sample of uncertain graduates, i.e., those students who do not have firm migration plans. The rather small number of students in the treatment group (especially when new EU students are used as the treated group) and the resulting large standard errors deteriorate the precision of the estimates. With this caveat in mind, there clearly appears to be a larger positive effect of the Article 50 news on intentions to leave for uncertain students than for all students from new EU member states. The point estimate is 0.235 and is significant at the 5 percent level without controls. It is still positive and greater than 0.2 (though not significant at conventional levels) with the complete set of controls. The estimated DDD coefficients show a similar positive effect of the Brexit notice on departure intentions among students from new EU countries who feel less certain about their future plans, despite being statistically weaker (columns 5-6, Panel B). Notably, the non-significant results found for the EU14 group in the full sample are now shown to be significant, with DID coefficients varying from 0.146 to 0.155 . This discouraging effect on 
post-study staying intentions gets more pronounced when we extend our analysis to the triple differences framework (columns 5-6, Panel C).

On balance, the results provide evidence that the "leaving" effects among EU graduates as a result of the UK triggering Article 50 are mainly driven by all students from new EU countries and uncertain students from EU14 countries. The considerable differences between different EU nationality groups are consistent with the fact that recent cohorts of migrants might be more impacted by Brexit and hence plan to leave faster.

\section{[Insert Table 9 here]}

\subsubsection{Student and school characteristics}

To further investigate treatment effect heterogeneity along student and school characteristics, we split our sample into different subgroups. Table 10 reports the results from the benchmark DID and DDD regressions for each subgroup of interest with the DID estimation based on the sample of uncertain graduates. ${ }^{19}$

Because sample sizes become rather small in the subgroup analysis, comparisons of the point estimates for the subgroups should be interpreted with caution. With that said, the estimates indicate that elder cohorts react more strongly to the news than younger cohorts (Panel A, Table 10). Therefore, it seems that the less mobile group of students are affected more by the notification letter. In Panel $\mathrm{B}$ we present the estimated effects for students studying STEM and non-STEM subjects. ${ }^{20}$ We see that the estimated effects of treatment on STEM graduates are lower and less statistically significant than the estimated effects obtained for non-STEM graduates in both double differences and triple differences specifications.

In Panel $\mathrm{C}$, we compare the estimates between undergraduate and postgraduate students. In both the DID and DDD models, the effect is driven by the group of postgraduate students.

\footnotetext{
${ }^{19}$ For the sake of parsimony, the estimation of the DID focuses on the group for which the evidence for "leaving" effects of the Brexit announcement is strongest - students whose post-study mobility intentions are uncertain.

${ }^{20}$ STEM subject areas as defined by HESA are: Medicine and dentistry; Subjects allied to medicine; Biological sciences; Veterinary science; Agriculture and related subjects; Physical sciences; Mathematical sciences; Computer science; Engineering and technology; and Architecture, building and planning.
} 
Considering that more than $80 \%$ of this group is represented by MSc students, one possible explanation for this result is that the invoking of Article 50 could hinder further education expectations (e.g., acquiring a postgraduate research degree in the UK). This explanation seems also compatible with what emerges from the analysis in Panel D, where we compare students by funding status which allows us to shed some light on the underlying mechanism behind the observed effect on intentions to leave. Many EU students, especially those with the intention to continue further study upon graduation, might worry that they will lose access to grants and/or tuition fee loans as a consequence of the UK's exit. If this were the case, we would expect to find stronger departure intentions amongst EU graduates who are currently being funded. Strikingly, the casual effect of invoking the Article 50 is very large and highly significant on students receiving scholarships and/or loan support. However, the respective casual effect on students without funding (i.e., those who are self-funded or rely on family provisions) is practically zero, with the coefficients being about one-third of the estimated effect size pertaining to funded students. These patterns are consistent with the aforementioned presumption, indicating that the potential loss of student funding from EU sources represents one channel through which the Article 50 notification can affect EU student mobility.

In Panel E of Table 10, the small and insignificant effect of treatment on students with high grade expectations as opposed to the strong deterrent effect on students with low grade expectations is not surprising, perhaps because the Brexit-induced economic shock is much greater for the latter students and they therefore see themselves as less employable in the graduate labour market.

The results, reported in the Panel F of Table 10, suggest a statistically significant effect of the treatment on students attending the Russell Group institutions, corresponding to about 32-35 percentage point increases in the probability of leaving. In comparison, the estimated effect on decisions to leave for students studying at a non-Russell Group university is positive, but far from being significant. One explanation for this asymmetric effect is that EU students from more prestigious universities may have a variety of outside options and would be more likely to leave if Britain looks less promising in terms of potential opportunities. 


\section{[Insert Table 10 here]}

\subsection{Further evidence based on the follow-up survey}

In this subsection we make use of unique information (namely observed location choices and a new module containing EU referendum questions) in the SoGIS follow-up survey to probe our results further in two aspects. ${ }^{21}$ First, we examine the extent to which international students' initial migration intentions as expressed before graduation are mapped into the actual migration behaviour. Second, the follow-up survey provides us with direct qualitative evidence on international student perceptions of the impact of Brexit, allowing us to explore the channels of the deterrent effect of the Article 50 letter on intentions to stay.

Our paper is interested in examining the immediate, short-run effect of the Article 50 notice on student mobility choices. One important aspect would be to understand the extent to which students stick to the migration plans that they have made before graduating. This is because it is possible that, even after a few months, the impact of the Article 50 news on students' effective decision to leave or stay could change if students get more information or a better understanding of the government's plans for Brexit. Fortunately, for participants in the second wave of SoGIS, we can check whether students who expressed their intention to leave eventually have left. Our tabulations show that $84 \%$ of all students who in the first wave said that they intended to leave the UK immediately after graduation have eventually left the country, with this figure being as high as $90 \%$ when we focus on EU students alone. ${ }^{22}$ While the focus of our paper is on the short-term impact of the Article 50 notification, we are also able to shed some light on its long-run consequences by showing that students' choices largely (despite not entirely) match their intentions.

We now turn to qualitative evidence from the survey on how the EU referendum affected international students' perceptions about the UK. Respondents who agreed that the EU

\footnotetext{
${ }^{21}$ The second wave of the SoGIS was conducted between December 2017 and February 2018. A total of 1,517 wave 1 respondents who had agreed to participate in the follow-up survey were recontacted and 563 students were successfully tracked. See Falkingham et al. (2018) for more details about the SoGIS wave 2 data.

${ }^{22}$ Similarly, $80 \%$ of all students and $90 \%$ of EU students who intended to stay in the UK report that they are still in the UK at the time of the second wave.
} 
referendum had made the UK a less attractive place to live in for non-UK nationals were asked to identify the reasons. In Table 11 we report the percentage of wave 2 respondents who indicated that certain factor(s) had been important in their stated opinions. We observe that the main reasons for decreased attractiveness of the UK as a living place relate to less welcoming climate, a potentially complex visa process and worse employment opportunities in the UK labour market after the EU referendum. The statistics presented here provide some suggestive evidence of how the triggering of the Brexit process may influence poststudy migration choices of international students. Further research is needed to gain a better insight into the channels of the impact of Brexit on international student mobility.

\section{[Insert Table 11 here]}

\section{Conclusions}

This paper provides the first evidence on how Brexit causally impacts the return intentions of EU students in the UK. On 29 March 2017, the UK government officially notified the EU of its intention to leave in a letter handed over to the European Council. This notification follows the EU referendum of 23 June 2016 and starts the two-year Brexit process under Article 50. We take advantage of this salient event as a natural experiment that quasi randomly allocates international students into treatment and control groups.

Using data from a new survey of graduating international students, we find that EU graduating students are significantly more likely than non-EU graduating students to plan on leaving the UK upon graduation immediately after the announcement. Interestingly, results are especially driven by students from the new EU countries and students from the EU14 countries who are uncertain about their migration plans. We further show that these effects are heterogeneous.

As a result of Brexit, EU students face unprecedented worries about future conditions affecting their costs, living standards and employability. Our study suggests that policyinduced uncertainty could have a powerful impact on micro-level decisions. Although the existing rights of EU students remain generally unchanged, they are likely to be different in 
the longer term, and rational decision makers will incorporate future conditions into current decision-making. This is consistent with the findings in Handley and Limao (2015) for firm's decisions under policy uncertainty.

Our results also add unique and policy relevant evidence on the impact of the Brexit on student mobility decisions. Furthermore, our findings carry relevant implications for other EU migrants in the UK who face more uncertainty, compared to students, in terms of their rights in post-Brexit UK, as well as other EU countries where politicians are calling for referendums in their own countries - a potential domino effect.

Our findings have important policy implications on the attractiveness of the UK for international, in particular, EU students. If the UK aims to continue to attract the best and the brightest, reducing uncertainty both in terms of rights but also economic prospects is vital. Thus, the UK government should take action to minimise the Brexit-induced uncertainties for EU nationals living in the UK by clarifying their rights and entitlements. Moreover, the results are particularly useful in informing policy in European countries where politicians voice support for their own national referendums driven by Brexit inspirations. 


\section{References}

Bahna, M. (2018). Study choices and returns of international students: On the role of cultural and economic capital of the family. Population, Space and Place 24(2), e2082.

Beine, M., R. Noël, and L. Ragot (2014). Determinants of the international mobility of students. Economics of Education review 41, 40-54.

Bijwaard, G. E. and Q. Wang (2016). Return migration of foreign students. European Journal of Population 32(1), 31-54.

Borjas, G. and B. Bratsberg (1996). Who Leaves? The Outmigration of the Foreign-Born. The Review of Economics and Statistics 78(1), 165-76.

de Coulon, A., D. Radu, and M. Friedrich Steinhardt (2016). Pane e cioccolata: The impact of native attitudes on return migration. Review of International Economics 24(2), 253281.

Dhingra, S., H. Huang, G. Ottaviano, J. P. Pessoa, T. Sampson, and J. V. Reenen (2017). The costs and benefits of leaving the EU: Trade effects. Economic Policy 32(92), 651-705.

Dhingra, S., G. Ottaviano, T. Sampson, and J. V. Reenen (2016a). The consequences of Brexit for UK trade and living standards. CEP Brexit Analysis No. 2, London: Centre for Economic Performance, London School of Economics.

Dhingra, S., G. Ottaviano, T. Sampson, and J. V. Reenen (2016b). The impact of Brexit on foreign investment in the UK. CEP Brexit Analysis No. 3, London: Centre for Economic Performance, London School of Economics.

Djajić, S. and R. Milbourne (1988). A general equilibrium model of guest-worker migration: The source-country perspective. Journal of international economics 25(3-4), 335-351.

Dustmann, C. (1997). Return migration, uncertainty and precautionary savings. Journal of Development Economics 52(2), 295-316. 
Dustmann, C., I. Fadlon, and Y. Weiss (2011). Return migration, human capital accumulation and the brain drain. Journal of Development Economics 95(1), 58-67.

Falkingham, J., C. Giulietti, J. Wahba, and C. Wang (2017). CPC-ONS-UUK Survey of Graduating International Students 2017. Technical report, Southampton: ESRC Centre for Population Change, University of Southampton. Available online at: http://www.cpc . ac.uk/docs/2017_SoGIS_Technical_Report.pdf.

Falkingham, J., C. Giulietti, J. Wahba, and C. Wang (2018). CPC-ONS-UUK Survey of Graduating International Students - Wave 2. Technical report, Southampton: ESRC Centre for Population Change, University of Southampton. Available online at: http: //www.cpc.ac.uk/docs/2018_SoGIS_Technical_Report\%20_Wave2.pdf.

Galor, O. and O. Stark (1991). The probability of return migration, migrants' work effort, and migrants' performance. Journal of Development Economics 35(2), 399-405.

González, C. R., R. B. Mesanza, and P. Mariel (2011). The determinants of international student mobility flows: An empirical study on the erasmus programme. Higher Education 62(4), 413-430.

Hainmueller, J. (2012). Entropy balancing for causal effects: A multivariate reweighting method to produce balanced samples in observational studies. Political Analysis 20(1), $25-46$.

Handley, K. and N. Limao (2015). Trade and investment under policy uncertainty: Theory and firm evidence. American Economic Journal: Economic Policy 7(4), 189-222.

Haupt, A., T. Krieger, and T. Lange (2016). Competition for the international pool of talent. Journal of Population Economics 29(4), 1113-1154.

Hazen, H. D. and H. C. Alberts (2006). Visitors or immigrants? International students in the United States. Population, Space and Place 12(3), 201-216.

Hill, J. K. (1987). Immigrant decisions concerning duration of stay and migratory frequency. Journal of development economics 25(1), 221-234. 
Manacorda, M., A. Manning, and J. Wadsworth (2012). The impact of immigration on the structure of wages: theory and evidence from Britain. Journal of the European economic association 10(1), 120-151.

Moreh, C., D. Mcghee, and A. Vlachantoni (2014). Should I stay or should I go? Strategies of EU citizens living in the UK in the context of the EU referendum. CPC Briefing Paper 35. ESRC Centre for Population Change, University of Southampton, Southampton, UK. Available online at: https://eprints.soton.ac.uk/394152/1/BP35_Should_ I_stay_or_should_I_go.pdf.

NIESR (2016). The short term economic impact of leaving the EU. National Institute Economic Review 236(1), 108-120.

OECD (2016). The economic consequences of Brexit: A taxing decision. OECD Economic Policy Papers. No. 16, Paris: OECD Publishing.

Portes, J. (2016). Immigration after Brexit. National Institute Economic Review 238(1), R13-R21.

Rosenzweig, M. R., D. A. Irwin, and J. G. Williamson (2006). Global wage differences and international student flows [with comments and discussion]. In Brookings trade forum, pp. 57-96. JSTOR.

Wadsworth, J., S. Dhingra, G. Ottaviano, and J. V. Reenen (2016). Brexit and the impact of immigration on the UK. CEP Brexit Analysis No. 5, London: Centre for Economic Performance, London School of Economics.

Wahba, J. (2014). Return migration and economic development,. In International Handbook on Migration and Economic Development, Robert E. B. Lucas, (ed.), Edward Elgar Publishing Ltd.

Yang, D. (2006). Why do migrants return to poor countries? Evidence from Philippine migrants' responses to exchange rate shocks. The Review of Economics and Statistics 88(4), $715-735$. 


\section{Figures and Tables}

Figure 1: Intention to Stay in / Leave the UK.

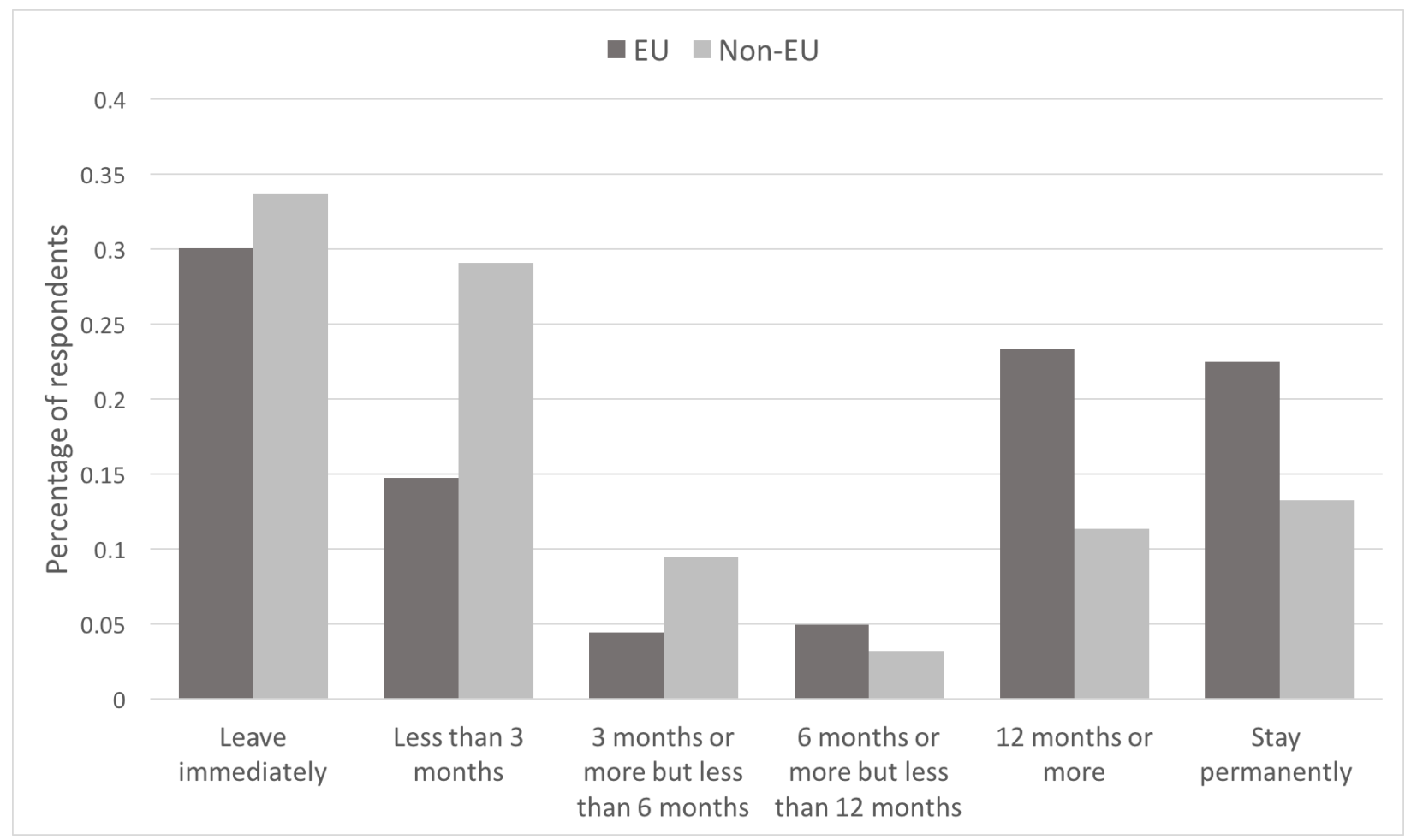

Source: SoGIS wave 1. 
Figure 2: Degree of Migration Intentions' Uncertainty.

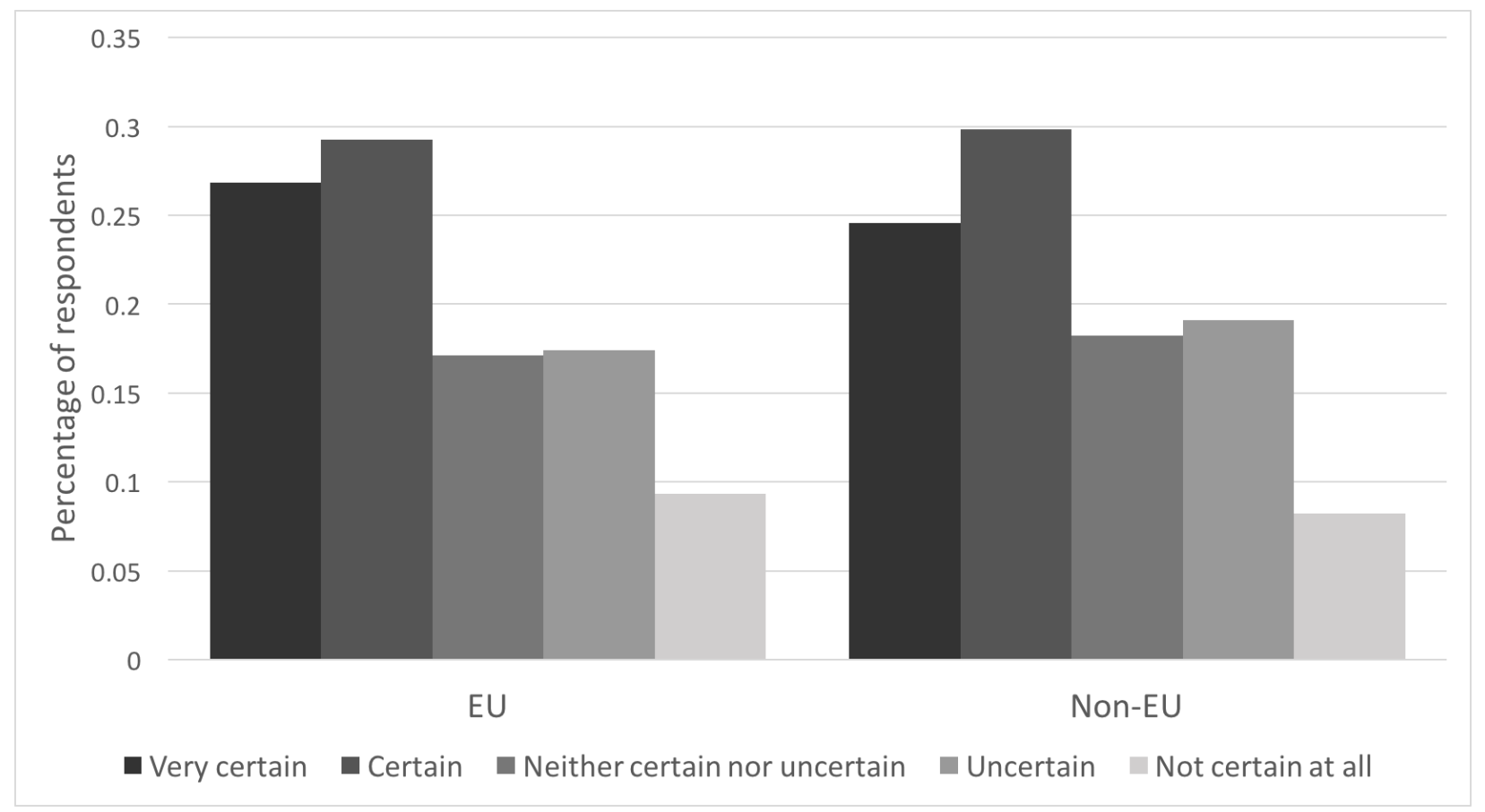

Source: SoGIS wave 1. 
Figure 3: Intentions to Leave.
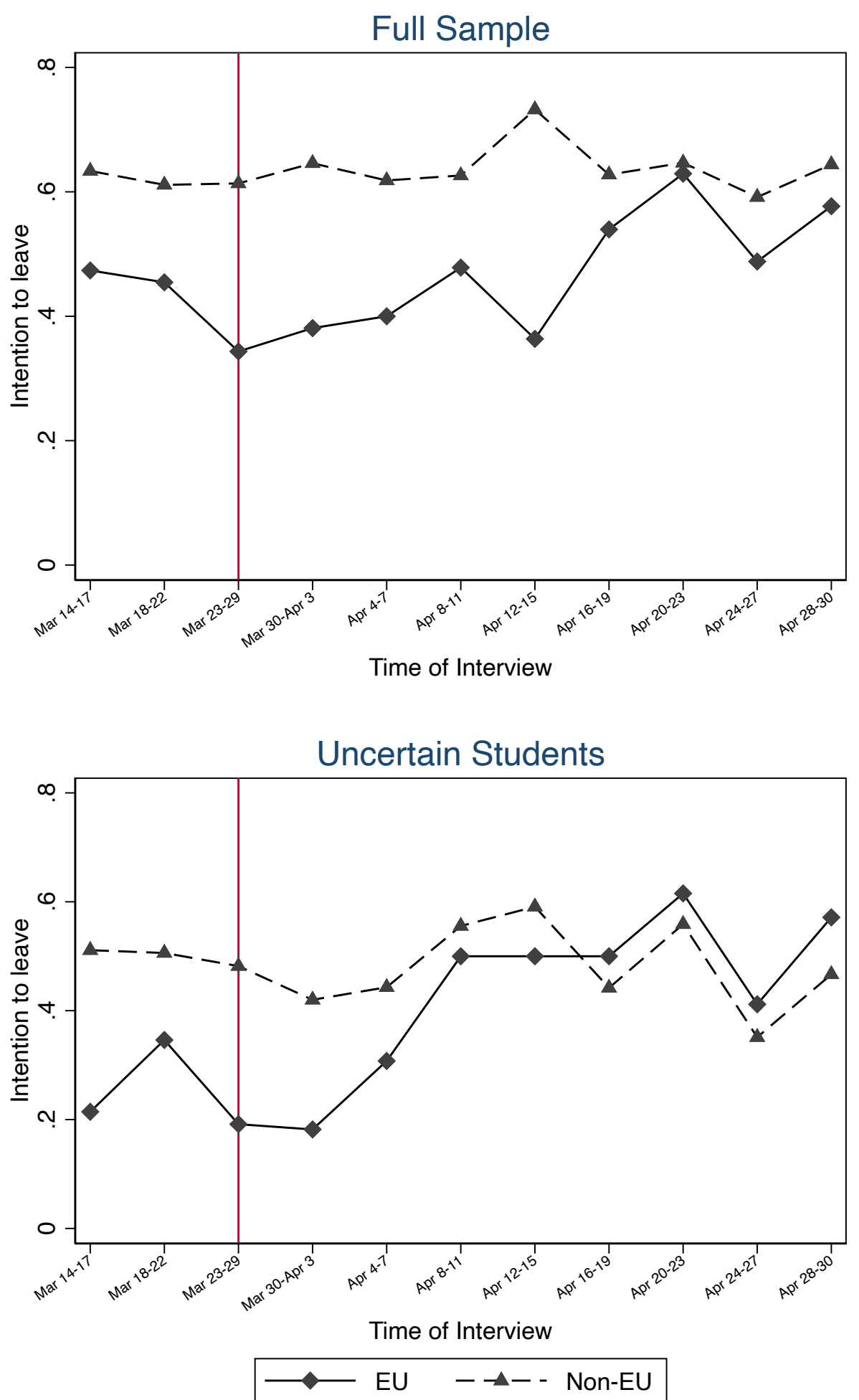

Notes: The underlying data sources and sample choices are described in Section 4. The average intention to leave the UK is plotted for the treated students and the control students. The red vertical line indicates the date of the Article 50 notification (March 29, 2017). 
Table 1: Summary Statistics - Full Sample

\begin{tabular}{|c|c|c|c|c|c|c|}
\hline & \multicolumn{3}{|c|}{ EU students } & \multicolumn{3}{|c|}{ Non-EU students } \\
\hline & $\begin{array}{c}\text { Pre- } \\
\text { A50 } \\
(1)\end{array}$ & $\begin{array}{c}\text { Post- } \\
\text { A50 } \\
(2)\end{array}$ & $\begin{array}{c}\text { Diff. } \\
(2)-(1)\end{array}$ & $\begin{array}{c}\text { Pre- } \\
\text { A50 } \\
(3)\end{array}$ & $\begin{array}{c}\text { Post- } \\
\text { A50 } \\
(4)\end{array}$ & $\begin{array}{c}\text { Diff. } \\
(4)-(3)\end{array}$ \\
\hline \multicolumn{7}{|l|}{ Dependent variable } \\
\hline Intention to leave & 0.40 & 0.48 & $0.08^{* *}$ & 0.62 & 0.63 & 0.02 \\
\hline \multicolumn{7}{|l|}{ Student background } \\
\hline Age & 25.06 & 24.87 & -0.19 & 26.73 & 26.35 & -0.38 \\
\hline Gender: Male $=1$ & 0.35 & 0.33 & -0.02 & 0.38 & 0.38 & -0.01 \\
\hline Gender: Female $=1$ & 0.63 & 0.66 & 0.02 & 0.61 & 0.61 & 0.00 \\
\hline Gender: Other $/$ missing $=1$ & 0.02 & 0.01 & -0.01 & 0.01 & 0.01 & 0.01 \\
\hline Single & 0.91 & 0.93 & 0.02 & 0.81 & 0.85 & $0.04^{* *}$ \\
\hline Works whilst studying & 0.37 & 0.35 & -0.02 & 0.23 & 0.24 & 0.01 \\
\hline Length of stay in the UK (years) & 2.47 & 2.40 & -0.07 & 1.93 & 1.92 & -0.01 \\
\hline Undergraduate & 0.38 & 0.36 & -0.02 & 0.28 & 0.26 & -0.02 \\
\hline Postgraduate & 0.48 & 0.46 & -0.02 & 0.66 & 0.66 & -0.01 \\
\hline Exchange students / Other degree & 0.14 & 0.18 & 0.04 & 0.05 & 0.08 & $0.03^{* *}$ \\
\hline Very good health & 0.47 & 0.46 & -0.01 & 0.42 & 0.39 & -0.03 \\
\hline \multicolumn{7}{|l|}{ Subjects of study } \\
\hline Medicine \& health sciences & 0.09 & 0.08 & -0.01 & 0.09 & 0.08 & -0.01 \\
\hline Natural sciences & 0.17 & 0.14 & -0.02 & 0.10 & 0.11 & 0.01 \\
\hline Mathematics \& computer sciences & 0.06 & 0.04 & -0.02 & 0.04 & 0.05 & 0.01 \\
\hline Engineering \& technology & 0.08 & 0.08 & -0.00 & 0.13 & 0.10 & $-0.03^{* *}$ \\
\hline Social sciences \& education & 0.41 & 0.39 & -0.02 & 0.47 & 0.47 & 0.01 \\
\hline Art \& humanities & 0.17 & 0.24 & $0.08 * * *$ & 0.14 & 0.16 & 0.02 \\
\hline Combined & 0.03 & 0.03 & 0.00 & 0.03 & 0.03 & -0.00 \\
\hline \multicolumn{7}{|l|}{ School characteristics } \\
\hline Russell Group & 0.33 & 0.60 & $0.27 * * *$ & 0.50 & 0.69 & $0.19^{* * *}$ \\
\hline Observations & 333 & 562 & & 815 & 1,347 & \\
\hline
\end{tabular}

Source.--SoGIS wave 1.

Notes.- The table contains sample means, broken down on whether the student is an EU or non-EU citizen. The summary statistics for the full list of universities are not reported due to confidentiality reasons.

$* / * * / * * *$ indicate difference in means between the two groups is statistically significant at the $0.1 / 0.05 / 0.01$ level. 
Table 2: Summary Statistics - Sample of Uncertain Students.

\begin{tabular}{|c|c|c|c|c|c|c|}
\hline & \multicolumn{3}{|c|}{ EU students } & \multicolumn{3}{|c|}{ Non-EU students } \\
\hline & $\begin{array}{c}\text { Pre- } \\
\text { A50 } \\
(1)\end{array}$ & $\begin{array}{c}\text { Post- } \\
\text { A50 } \\
(2)\end{array}$ & $\begin{array}{l}\text { Diff. } \\
(2)-(1)\end{array}$ & $\begin{array}{l}\text { Pre- } \\
\text { A50 } \\
(3)\end{array}$ & $\begin{array}{c}\text { Post- } \\
\text { A50 } \\
(4)\end{array}$ & $\begin{array}{l}\text { Diff. } \\
(4)-(3)\end{array}$ \\
\hline \multicolumn{7}{|l|}{ Dependent variable } \\
\hline Intention to leave & 0.24 & 0.39 & $0.15^{* *}$ & 0.50 & 0.46 & -0.03 \\
\hline \multicolumn{7}{|l|}{ Student background } \\
\hline Age & 25.47 & 24.45 & $-1.02^{* *}$ & 26.27 & 26.19 & -0.08 \\
\hline Male & 0.36 & 0.29 & -0.07 & 0.33 & 0.38 & 0.04 \\
\hline Female & 0.61 & 0.70 & 0.09 & 0.66 & 0.61 & -0.04 \\
\hline Gender: Other $/$ missing $=1$ & 0.03 & 0.01 & -0.02 & 0.01 & 0.01 & 0.00 \\
\hline Single & 0.92 & 0.98 & $0.06^{* *}$ & 0.85 & 0.91 & $0.06^{* *}$ \\
\hline Works whilst studying & 0.34 & 0.30 & -0.05 & 0.26 & 0.26 & 0.00 \\
\hline Length of stay in the UK (years) & 2.12 & 2.27 & 0.15 & 1.91 & 1.98 & 0.07 \\
\hline Undergraduate & 0.36 & 0.38 & 0.03 & 0.25 & 0.25 & -0.00 \\
\hline Postgraduate & 0.53 & 0.48 & -0.05 & 0.68 & 0.70 & 0.02 \\
\hline Very good health & 0.45 & 0.47 & 0.02 & 0.36 & 0.37 & 0.01 \\
\hline Exchange students / Other degree & 0.11 & 0.13 & 0.02 & 0.06 & 0.04 & -0.02 \\
\hline \multicolumn{7}{|l|}{ Subjects of study } \\
\hline Medicine \& health sciences & 0.13 & 0.08 & -0.05 & 0.06 & 0.07 & 0.01 \\
\hline Natural sciences & 0.17 & 0.13 & -0.04 & 0.10 & 0.11 & 0.01 \\
\hline Mathematics \& computer science & 0.09 & 0.04 & $-0.06 *$ & 0.04 & 0.06 & 0.02 \\
\hline Engineering \& technology & 0.08 & 0.05 & -0.03 & 0.15 & 0.08 & $-0.07^{* *}$ \\
\hline Social sciences \& education & 0.38 & 0.36 & -0.02 & 0.46 & 0.48 & 0.02 \\
\hline Art \& humanities & 0.14 & 0.32 & $0.18^{* * *}$ & 0.14 & 0.19 & 0.04 \\
\hline Combined & 0.01 & 0.03 & 0.02 & 0.05 & 0.02 & $-0.03^{* *}$ \\
\hline \multicolumn{7}{|l|}{ School characteristics } \\
\hline Russell Group & 0.32 & 0.60 & $0.28^{* * *}$ & 0.56 & 0.71 & $0.15^{* * * *}$ \\
\hline Observations & 87 & 141 & & 212 & 378 & \\
\hline
\end{tabular}

Source.--SoGIS wave 1 .

Notes.-The table contains sample means, broken down on whether the student is an EU or non-EU citizen. Sample restricted to students who do not have firm migration plans. The summary statistics for the full list of universities are not reported due to confidentiality reasons.

$* / * * / * * *$ indicate difference in means between the two groups is statistically significant at the $0.1 / 0.05 / 0.01$ level. 
Table 3: Estimates of the Effect of Brexit Notification on Return Intentions.

\begin{tabular}{|c|c|c|c|c|c|c|}
\hline \multicolumn{7}{|c|}{ Dependent Variable: Intention to leave the UK after graduation } \\
\hline & \multicolumn{3}{|c|}{ Full Sample } & \multicolumn{3}{|c|}{ Uncertain Students } \\
\hline & (1) & $(2)$ & $(3)$ & $(4)$ & $(5)$ & $(6)$ \\
\hline \multirow[t]{2}{*}{$\mathrm{EU} \times$ Post } & 0.061 & 0.053 & $0.072 * *$ & $0.184^{* *}$ & $0.162 * *$ & $0.180^{* * *}$ \\
\hline & $(0.046)$ & $(0.036)$ & $(0.036)$ & $(0.078)$ & $(0.066)$ & $(0.064)$ \\
\hline \multirow[t]{2}{*}{$\mathrm{EU}$} & $-0.214^{* * *}$ & $-0.184^{* * *}$ & $-0.192^{* * *}$ & $-0.254^{* * *}$ & $-0.258^{* * *}$ & $-0.226^{* * *}$ \\
\hline & $(0.043)$ & $(0.044)$ & $(0.042)$ & $(0.057)$ & $(0.062)$ & $(0.062)$ \\
\hline \multirow[t]{2}{*}{ Post } & 0.015 & 0.011 & 0.026 & -0.035 & -0.023 & 0.063 \\
\hline & $(0.020)$ & $(0.023)$ & $(0.028)$ & $(0.045)$ & $(0.044)$ & $(0.046)$ \\
\hline \multirow[t]{2}{*}{ Age } & & 0.002 & 0.001 & & -0.004 & -0.001 \\
\hline & & $(0.002)$ & $(0.002)$ & & $(0.004)$ & $(0.004)$ \\
\hline \multirow[t]{2}{*}{ Female } & & -0.016 & -0.046 & & 0.056 & 0.022 \\
\hline & & $(0.067)$ & $(0.072)$ & & $(0.108)$ & $(0.114)$ \\
\hline \multirow{2}{*}{ Male } & & 0.017 & -0.015 & & 0.032 & -0.010 \\
\hline & & $(0.066)$ & $(0.071)$ & & $(0.111)$ & $(0.123)$ \\
\hline \multirow[t]{2}{*}{ Single } & & -0.030 & -0.019 & & -0.043 & -0.019 \\
\hline & & $(0.025)$ & $(0.026)$ & & $(0.049)$ & $(0.051)$ \\
\hline \multirow[t]{2}{*}{ Works whilst studying } & & $-0.133^{* * *}$ & $-0.141^{* * *}$ & & $-0.078^{* *}$ & $-0.060^{*}$ \\
\hline & & $(0.016)$ & $(0.016)$ & & $(0.032)$ & $(0.033)$ \\
\hline \multirow[t]{2}{*}{ Length of stay in the UK (years) } & & $-0.040^{* * *}$ & $-0.040^{* * *}$ & & $-0.038^{* * *}$ & $-0.032^{* * *}$ \\
\hline & & $(0.006)$ & $(0.006)$ & & $(0.009)$ & $(0.009)$ \\
\hline \multirow[t]{2}{*}{ Undergraduate } & & $-0.234^{* * *}$ & $-0.244^{* * *}$ & & $-0.262^{* * *}$ & $-0.270^{* * *}$ \\
\hline & & $(0.035)$ & $(0.030)$ & & $(0.074)$ & $(0.072)$ \\
\hline \multirow[t]{2}{*}{ Postgraduate } & & $-0.232^{* * *}$ & $-0.221^{* * *}$ & & $-0.314^{* * *}$ & $-0.303^{* * *}$ \\
\hline & & $(0.037)$ & $(0.036)$ & & $(0.059)$ & $(0.055)$ \\
\hline \multirow[t]{2}{*}{ Very good health } & & $-0.034^{*}$ & $-0.034^{*}$ & & -0.021 & -0.011 \\
\hline & & $(0.018)$ & $(0.018)$ & & $(0.035)$ & $(0.035)$ \\
\hline Mean of dep. var. & 0.57 & 0.57 & 0.57 & 0.43 & 0.43 & 0.43 \\
\hline$R^{2}$ & .028 & .105 & .13 & .023 & .083 & .169 \\
\hline Observations & 3,057 & 3,057 & 3,057 & 818 & 818 & 818 \\
\hline Number of clusters & 45 & 45 & 45 & 45 & 45 & 45 \\
\hline Background controls & No & Yes & Yes & No & Yes & Yes \\
\hline Subject FE & No & No & Yes & No & No & Yes \\
\hline University FE & No & No & Yes & No & No & Yes \\
\hline
\end{tabular}


Table 4: Effect of Article 50 on uncertainty.

Dep. Var.: Dummy for being uncertain

\begin{tabular}{lrr}
\hline & \multicolumn{1}{c}{$(1)$} & \multicolumn{1}{c}{$(2)$} \\
\hline $\mathrm{EU} \times$ Post & -0.031 & -0.045 \\
$\mathrm{EU}$ & $(0.038)$ & $(0.038)$ \\
& 0.001 & 0.003 \\
Post & $(0.036)$ & $(0.040)$ \\
& 0.021 & 0.026 \\
$R^{2}$ & $(0.016)$ & $(0.023)$ \\
Observations & .001 & .032 \\
\hline Background controls & 3,057 & 3,057 \\
Subject FE & No & Yes \\
University FE & No & Yes \\
\hline
\end{tabular}

Source.--SoGIS wave 1 .

Notes.-The dependent variable is a dummy indicating whether the student does not have firm migration plans. Column (2) includes student background controls, subject fixed effects and university fixed effects. Student background variables used as controls include age, gender dummies, marital status, a dummy for whether the student is working alongside study, length of stay in the UK, dummy indicators for programme of study, and health status.

Robust standard errors in parentheses are clustered at the university level.

Significance levels: ${ }^{*} p<0.1,{ }^{* *} p<0.05,{ }^{* * *} p<0.01$. 
Table 5: Placebo Difference-in-Differences.

\begin{tabular}{|c|c|c|c|c|c|c|c|c|}
\hline & \multicolumn{4}{|c|}{$\begin{array}{l}\text { Pseudo cut-off date: } \\
\text { March } 19,2017\end{array}$} & \multicolumn{4}{|c|}{$\begin{array}{l}\text { Pseudo outcome: } \\
\text { Participate in prize draw }\end{array}$} \\
\hline & \multicolumn{2}{|c|}{ Full Sample } & \multicolumn{2}{|c|}{ Uncertain Students } & \multicolumn{2}{|c|}{ Full Sample } & \multicolumn{2}{|c|}{ Uncertain Students } \\
\hline & (1) & $(2)$ & $(3)$ & (4) & $(5)$ & (6) & $(7)$ & (8) \\
\hline \multirow{2}{*}{$\mathrm{EU} \times$ Post } & -0.114 & -0.099 & -0.087 & -0.005 & -0.037 & -0.022 & -0.046 & -0.069 \\
\hline & $(0.078)$ & $(0.076)$ & $(0.125)$ & $(0.129)$ & $(0.034)$ & $(0.033)$ & $(0.070)$ & $(0.079)$ \\
\hline \multirow[t]{2}{*}{$\mathrm{EU}$} & $-0.157^{* * *}$ & $-0.147^{* *}$ & $-0.204^{* *}$ & $-0.214^{* *}$ & 0.009 & -0.002 & -0.008 & 0.011 \\
\hline & $(0.051)$ & $(0.063)$ & $(0.083)$ & $(0.082)$ & $(0.028)$ & $(0.028)$ & $(0.063)$ & $(0.065)$ \\
\hline \multirow[t]{2}{*}{ Post } & -0.004 & 0.012 & -0.022 & -0.052 & 0.005 & $-0.075^{* * *}$ & -0.003 & -0.063 \\
\hline & $(0.037)$ & $(0.054)$ & $(0.081)$ & $(0.103)$ & $(0.028)$ & $(0.026)$ & $(0.044)$ & $(0.065)$ \\
\hline$R^{2}$ & .042 & .138 & .058 & .221 & .001 & .057 & .003 & .115 \\
\hline Observations & 1,148 & 1,148 & 299 & 299 & 2,822 & 2,822 & 747 & 747 \\
\hline Background controls & $\mathrm{No}$ & Yes & $\mathrm{No}$ & Yes & No & Yes & $\mathrm{No}$ & Yes \\
\hline Subject FE & No & Yes & No & Yes & No & Yes & No & Yes \\
\hline University FE & No & Yes & No & Yes & No & Yes & No & Yes \\
\hline \multicolumn{9}{|c|}{$\begin{array}{l}\text { SOURCE. - SoGIS wave } 1 . \\
\text { NoTES.-The table reports difference-in-differences estimates of the pseudo treatment effect. The dependent variable is a dummy for whether the student intends to } \\
\text { leave the UK after graduation (columns } 1-4 \text { ) and for whether the student wishes to take part in the survey prize draw (columns } 5-8 \text { ). In columns }(1)-(4) \text { only data } \\
\text { preceding the cut-off date of the Article } 50 \text { notification are used, and the Post dummy is set equal to one from } 20 \text { March } 2017 \text { to } 29 \text { March } 2017 \text {. Columns }(1) \text {, (2), (5) } \\
\text { and (6) use the full sample of students, while columns }(3),(4),(7) \text { and }(8) \text { restrict the analysis to the subsample of students who do not have firm migration plans. The } \\
\text { even columns include student background controls, subject fixed effects and university fixed effects. Student background variables used as controls include age, gender } \\
\text { dummies, marital status, a dummy for whether the student is working alongside study, length of stay in the UK, dummy indicators for programme of study, and health } \\
\text { status. } \\
\text { Robust standard errors in parentheses are clustered at the university level. } \\
\text { Significance levels: }{ }^{*} p<0.1,{ }^{* *} p<0.05,{ }^{* * *} p<0.01 \text {. }\end{array}$} \\
\hline
\end{tabular}


Table 6: Robustness Checks: Weighted Estimates.

\begin{tabular}{|c|c|c|c|}
\hline \multicolumn{4}{|c|}{ Dependent Variable: Intention to leave the UK after graduation } \\
\hline & $\begin{array}{c}\text { Naive } \\
\text { DID } \\
\text { (benchmark) }\end{array}$ & $\begin{array}{c}\text { DID with } \\
\text { PS } \\
\text { weighting }\end{array}$ & $\begin{array}{c}\text { DID with } \\
\text { entropy } \\
\text { balancing }\end{array}$ \\
\hline & $(1)$ & $(2)$ & $(3)$ \\
\hline \multicolumn{4}{|l|}{ A. Full Sample } \\
\hline $\mathrm{EU} \times$ Post & $\begin{array}{l}0.072^{* *} \\
(0.036)\end{array}$ & $\begin{array}{l}0.076^{* *} \\
(0.035)\end{array}$ & $\begin{array}{l}0.076^{* *} \\
(0.035)\end{array}$ \\
\hline$R^{2}$ & .13 & .169 & .177 \\
\hline Observations & 3,057 & 3,057 & 3,057 \\
\hline \multicolumn{4}{|c|}{ B. Uncertain Students } \\
\hline $\mathrm{EU} \times$ Post & $\begin{array}{l}0.180^{* * *} \\
(0.064)\end{array}$ & $\begin{array}{c}0.147^{* *} \\
(0.073)\end{array}$ & $\begin{array}{l}0.230^{* *} \\
(0.087)\end{array}$ \\
\hline$R^{2}$ & .169 & .244 & .257 \\
\hline Observations & 818 & 818 & 818 \\
\hline Background controls & Yes & Yes & Yes \\
\hline Subject FE & Yes & Yes & Yes \\
\hline University FE & Yes & Yes & Yes \\
\hline
\end{tabular}

Source.- SoGIS wave 1 .

Notes.-The table reports the estimated treatment effect from four separate difference-indifferences specifications estimated by OLS controlling for the standard set of student background variables and fixed effects as in the original DID regressions in the main specification. Uncertain students refers to students who do not have firm migration plans

Col 1: simple difference-in-differences without matching/reweighting, corresponding to the main specification in the last column of Table 3;

Col 2: propensity score weighted difference-in-differences, with propensity score weights estimated separately at each time point;

Col 3: entropy weighted difference-in-differences, with entropy weights estimated separately at each time point.

Robust standard errors in parentheses are clustered at the university level.

Significance levels: ${ }^{*} p<0.1,{ }^{* *} p<0.05,{ }^{* * *} p<0.01$. 
Table 7: Robustness Checks: Difference-in-Difference-inDifferences.

Dep. Var.: Intention to leave the UK after graduation

(1)

\begin{tabular}{lcc}
\hline EU $\times$ Post $\times$ Uncertain & $0.174^{* *}$ & $0.168^{* *}$ \\
EU $\times$ Post & $0.080)$ & $(0.075)$ \\
& $(0.047)$ & 0.020 \\
Post $\times$ Uncertain & -0.074 & -0.054 \\
& $(0.048)$ & $(0.046)$ \\
EU $\times$ Uncertain & -0.055 & -0.064 \\
& $(0.073)$ & $(0.070)$ \\
EU & $-0.199^{* * *}$ & $-0.175^{* * *}$ \\
& $(0.053)$ & $(0.048)$ \\
Post & $0.039^{*}$ & 0.047 \\
& $(0.021)$ & $(0.028)$ \\
Uncertain & $-0.163^{* * *}$ & $-0.162^{* * *}$ \\
& $(0.041)$ & $(0.039)$ \\
$R^{2}$ & .06 & .158 \\
Observations & 3,057 & 3,057 \\
\hline Background controls & No & Yes \\
Subject FE & No & Yes \\
University FE & No & Yes \\
\hline
\end{tabular}

Source.-SoGIS wave 1 .

Notes.-The table reports results from difference-in-difference-in-differences specifications estimated by OLS. Column (2) includes student background controls, subject fixed effects and university fixed effects. Student background variables used as controls include age, gender dummies, marital status, a dummy for whether the student is working alongside study, length of stay in the UK, dummy indicators for programme of study, and health status.

Robust standard errors in parentheses are clustered at the university level.

Significance levels: ${ }^{*} p<0.1,{ }^{* *} p<0.05,{ }^{* * *} p<0.01$. 
Table 8: Robustness Checks: Excluding the Day of Article 50 Notification.

\begin{tabular}{|c|c|c|c|c|c|c|}
\hline \multicolumn{7}{|c|}{ Dependent Variable: Intention to leave the UK after graduation } \\
\hline & \multicolumn{3}{|c|}{ Full Sample } & \multicolumn{3}{|c|}{ Uncertain Students } \\
\hline & $(1)$ & $(2)$ & $(3)$ & $(4)$ & $(5)$ & $(6)$ \\
\hline \multirow[t]{2}{*}{$\mathrm{EU} \times$ Post } & 0.031 & 0.019 & 0.039 & $0.178^{* *}$ & $0.146^{* *}$ & $0.187^{* * *}$ \\
\hline & $(0.047)$ & $(0.036)$ & $(0.036)$ & $(0.082)$ & $(0.071)$ & $(0.066)$ \\
\hline \multirow[t]{2}{*}{$\mathrm{EU}$} & $-0.183^{* * *}$ & $-0.152^{* * *}$ & $-0.161^{* * *}$ & $-0.249^{* * *}$ & $-0.241^{* * *}$ & $-0.232^{* * *}$ \\
\hline & $(0.043)$ & $(0.043)$ & $(0.041)$ & $(0.064)$ & $(0.069)$ & $(0.070)$ \\
\hline \multirow[t]{2}{*}{ Post } & 0.018 & 0.014 & 0.038 & -0.053 & -0.040 & 0.044 \\
\hline & $(0.022)$ & $(0.024)$ & $(0.032)$ & $(0.046)$ & $(0.045)$ & $(0.051)$ \\
\hline Mean of dep. var. & 0.58 & 0.58 & 0.58 & 0.44 & 0.44 & 0.44 \\
\hline$R^{2}$ & .023 & .101 & .128 & .019 & .08 & .166 \\
\hline Observations & 2,926 & 2,926 & 2,926 & 774 & 774 & 774 \\
\hline Number of clusters & 45 & 45 & 45 & 45 & 45 & 45 \\
\hline Background controls & No & Yes & Yes & No & Yes & Yes \\
\hline Subject FE & No & No & Yes & No & No & Yes \\
\hline University FE & No & No & Yes & No & No & Yes \\
\hline
\end{tabular}


Table 9: Heterogeneity: EU Nationality Groups.

\begin{tabular}{|c|c|c|c|c|c|c|}
\hline \multicolumn{7}{|c|}{ Dependent Variable: Intention to leave the UK after graduation } \\
\hline & \multicolumn{4}{|c|}{ Difference-in-differences } & \multicolumn{2}{|c|}{ Triple differences } \\
\hline & \multicolumn{2}{|c|}{ Full Sample } & \multicolumn{2}{|c|}{ Uncertain Students } & \multirow[b]{2}{*}{$(5)$} & \multirow[b]{2}{*}{$(6)$} \\
\hline & $(1)$ & $(2)$ & (3) & (4) & & \\
\hline A. All EU & & & & & & \\
\hline $\mathrm{EU} \times$ Post & $\begin{array}{r}0.061 \\
(0.046)\end{array}$ & $\begin{array}{l}0.072^{* *} \\
(0.036)\end{array}$ & $\begin{array}{l}0.184^{* *} \\
(0.078)\end{array}$ & $\begin{array}{l}0.180^{* * *} \\
(0.064)\end{array}$ & & \\
\hline EU $\times$ Post $\times$ Uncertain & & & & & $\begin{array}{l}0.174^{* *} \\
(0.080)\end{array}$ & $\begin{array}{l}0.168^{* *} \\
(0.075)\end{array}$ \\
\hline$R^{2}$ & .028 & .13 & .023 & .169 & .06 & .158 \\
\hline Observations & 3,057 & 3,057 & 818 & 818 & 3,057 & 3,057 \\
\hline \multicolumn{7}{|l|}{ B. New EU } \\
\hline New $\mathrm{EU} \times$ Post & $\begin{array}{l}0.141^{* * *} \\
(0.042)\end{array}$ & $\begin{array}{l}0.150^{* * *} \\
(0.046)\end{array}$ & $\begin{array}{l}0.235^{* *} \\
(0.113)\end{array}$ & $\begin{array}{r}0.213 \\
(0.138)\end{array}$ & & \\
\hline New EU $\times$ Post $\times$ Uncertain & & & & & $\begin{array}{r}0.136 \\
(0.134)\end{array}$ & $\begin{array}{r}0.169 \\
(0.163)\end{array}$ \\
\hline$R^{2}$ & .046 & .127 & .03 & .176 & .081 & .158 \\
\hline Observations & 2,382 & 2,382 & 634 & 634 & 2,382 & 2,382 \\
\hline \multicolumn{7}{|l|}{ C. $E U 14$} \\
\hline EU14 $\times$ Post & $\begin{array}{r}0.023 \\
(0.057)\end{array}$ & $\begin{array}{r}0.037 \\
(0.045)\end{array}$ & $\begin{array}{c}0.155^{*} \\
(0.086)\end{array}$ & $\begin{array}{l}0.146^{* *} \\
(0.067)\end{array}$ & & \\
\hline EU14 $\times$ Post $\times$ Uncertain & & & & & $\begin{array}{l}0.188^{* *} \\
(0.076)\end{array}$ & $\begin{array}{l}0.175^{* *} \\
(0.066)\end{array}$ \\
\hline$R^{2}$ & .011 & .114 & .011 & .17 & .047 & .145 \\
\hline Observations & 2,837 & 2,837 & 774 & 774 & 2,837 & 2,837 \\
\hline Difference New EU - EU14 (p-value) & 0.13 & 0.09 & 0.52 & 0.62 & 0.72 & 0.97 \\
\hline Background controls & No & Yes & No & Yes & No & Yes \\
\hline Subject FE & No & Yes & No & Yes & No & Yes \\
\hline University FE & No & Yes & No & Yes & No & Yes \\
\hline
\end{tabular}


Table 10: Heterogeneity: Student and School Characteristics.

\begin{tabular}{|c|c|c|c|c|c|c|}
\hline \multicolumn{7}{|c|}{ Dependent Variable: Intention to leave the UK after graduation } \\
\hline & DID & DDD & DID & DDD & Diff (1)-(3) & Diff $(2)-(4)$ \\
\hline & $(1)$ & $(2)$ & $(3)$ & $(4)$ & p-val & p-val \\
\hline A: Age & \multicolumn{2}{|c|}{ Age $18-24$} & \multicolumn{2}{|c|}{ Age $24+$} & \multirow{5}{*}{0.22} & \multirow{5}{*}{0.62} \\
\hline \multirow{2}{*}{ Treatment effect } & 0.070 & 0.121 & $0.255^{* *}$ & $0.202^{* *}$ & & \\
\hline & $(0.125)$ & $(0.131)$ & $(0.087)$ & $(0.088)$ & & \\
\hline$R^{2}$ & .236 & .211 & .217 & .155 & & \\
\hline Observations & 368 & 1,388 & 450 & 1,669 & & \\
\hline \multirow{3}{*}{$\begin{array}{l}\text { B: Fields of study } \\
\text { Treatment effect }\end{array}$} & \multicolumn{2}{|c|}{ Non-STEM } & \multicolumn{2}{|c|}{ STEM } & \multirow{5}{*}{0.12} & \multirow{5}{*}{0.33} \\
\hline & $0.262^{* *}$ & $0.225^{* * *}$ & 0.065 & 0.081 & & \\
\hline & $(0.016)$ & $(0.022)$ & $(0.190)$ & $(0.121)$ & & \\
\hline$R^{2}$ & .208 & .168 & .277 & .182 & & \\
\hline Observations & 518 & 1,921 & 300 & 1,136 & & \\
\hline \multirow{3}{*}{$\begin{array}{l}\text { C: Type of degree } \\
\text { Treatment effect }\end{array}$} & \multicolumn{2}{|c|}{ Undergraduate } & \multicolumn{2}{|c|}{ Postgraduate } & \multirow{5}{*}{0.11} & \multirow{5}{*}{0.51} \\
\hline & 0.007 & 0.088 & $0.267^{* *}$ & $0.214^{*}$ & & \\
\hline & $(0.130)$ & $(0.120)$ & $(0.075)$ & $(0.108)$ & & \\
\hline$R^{2}$ & .278 & .174 & .171 & .151 & & \\
\hline Observations & 235 & 912 & 524 & 1,845 & & \\
\hline \multirow{3}{*}{$\begin{array}{l}\text { D: Sources of funding } \\
\text { Treatment effect }\end{array}$} & \multicolumn{2}{|c|}{ No grants/loans } & \multicolumn{2}{|c|}{ With grants/loans } & & \\
\hline & 0.101 & 0.103 & $0.293^{* *}$ & $0.313^{* *}$ & & \\
\hline & $(0.102)$ & $(0.095)$ & $(0.119)$ & $(0.133)$ & 0.20 & 0.21 \\
\hline$R^{2}$ & .211 & .164 & .296 & .216 & & \\
\hline Observations & 501 & 1,688 & 317 & 1,369 & & \\
\hline \multirow{3}{*}{$\begin{array}{l}\text { E: Expected final grade } \\
\text { Treatment effect }\end{array}$} & \multicolumn{2}{|c|}{ Low } & \multicolumn{2}{|c|}{ High } & \multirow{5}{*}{0.01} & \multirow{5}{*}{0.08} \\
\hline & $0.242^{* *}$ & $0.232^{* *}$ & -0.100 & 0.038 & & \\
\hline & $(0.084)$ & $(0.094)$ & $(0.138)$ & $(0.129)$ & & \\
\hline$R^{2}$ & .221 & .165 & .344 & .217 & & \\
\hline Observations & 606 & 2,249 & 212 & 807 & & \\
\hline \multirow{3}{*}{$\begin{array}{l}\text { F: Type of university } \\
\text { Treatment effect }\end{array}$} & \multicolumn{2}{|c|}{ Non-Russell Group } & \multicolumn{2}{|c|}{ Russell Group } & \multirow{5}{*}{0.02} & \\
\hline & 0.062 & 0.068 & $0.350^{* *}$ & $0.316^{* *}$ & & \\
\hline & $(0.104)$ & $(0.103)$ & $(0.088)$ & $(0.103)$ & & 0.19 \\
\hline$R^{2}$ & .258 & .193 & .131 & .137 & & \\
\hline Observations & 319 & 1,283 & 499 & 1,774 & & \\
\hline Background controls & Yes & Yes & Yes & Yes & & \\
\hline Subject FE & Yes & Yes & Yes & Yes & & \\
\hline University FE & Yes & Yes & Yes & Yes & & \\
\hline
\end{tabular}


Table 11: Reasons for UK's Decreased Attractiveness.

\begin{tabular}{lrr}
\hline & Full & Uncertain \\
& Sample & Students \\
\hline Less welcoming climate & 0.76 & $(2)$ \\
\hline & $(0.43)$ & 0.75 \\
Complex visa process & 0.66 & 0.62 \\
& $(0.48)$ & $(0.49)$ \\
Worse employment prospects & 0.64 & 0.62 \\
& $(0.48)$ & $(0.49)$ \\
Reduced ethnic diversity & 0.31 & 0.33 \\
& $(0.47)$ & $(0.48)$ \\
Reduced social cohesion & 0.52 & 0.42 \\
& $(0.50)$ & $(0.50)$ \\
UK will be weaker in Europe & 0.57 & 0.54 \\
& $(0.50)$ & $(0.51)$ \\
Other reasons & 0.01 & 0.04 \\
& $(0.10)$ & $(0.20)$ \\
\hline Observations & 99 & 24 \\
\hline
\end{tabular}

Source.--SoGIS wave 2.

Notes.- The statistics are based on all respondents from the follow-up survey who agreed that the EU referendum had made the UK a less attractive place to live in for non-UK nationals. Column (2) further restricts the sample to respondents who do not have firm migration plans in wave 1. The table shows percentage of respondents who indicate that a particular reason led them to hold the opinion. 


\section{Appendix A The Article 50 Letter $^{23}$}

To provide a brief background, Article 50 of the Treaty on European Union (TEU) ${ }^{24}$ is the only legal mechanism by which a member state can withdraw from the European Union. The main parts of the Treaty say as follows:

Paragraph 1: "Any Member State may decide to withdraw from the Union in accordance with its own constitutional requirements."

Paragraph 2: "A Member State which decides to withdraw shall notify the European Council of its intention [. . .] the Union shall negotiate and conclude an agreement with that State, setting out the arrangements for its withdrawal, taking account of the framework for its future relationship with the Union."

Paragraph 3: "The Treaties shall cease to apply to the State in question from the date of entry into force of the withdrawal agreement or, failing that, two years after the notification referred to in paragraph 2, unless the European Council, in agreement with the Member State concerned, unanimously decides to extend this period."

Indeed, no country had ever invoked Article 50 TEU until 29 March 2017, when the British Prime Minister Theresa May triggered it with a six-page letter sent to the President of the European Council Donald Tusk, formally launching the two-year exit negotiation process (see Figure A.1). Despite a clear referendum result, there exists no prior legislation as to how and when this result will be implemented. In such a precarious context, the official notice under Article 50 becomes crucial. It is the first step in the three-phase Brexit model ${ }^{25}$ and a cut-off point at which an initial deadline for the UK's departure from the EU is set, i.e., 29 March 2019. It is also a point of "no return" - after triggering Article 50, the UK should act on the assumption that it cannot unilaterally retract unless all member states agree to its revocation.

\footnotetext{
${ }^{23}$ In the paper, we use the two terms "Article 50 letter" and "Brexit letter" interchangeably.

${ }^{24}$ Article 50 was inserted into the Treaty on European Union by the Treaty of Lisbon, which came into force in December 2009.

${ }^{25}$ The process of Brexit is complex and lengthy, which can be broken down into three phases. The first phase is the triggering of Article 50. The second phase is the negotiation process per se. The third and final phase will be agreement to the withdrawal package and the "new relationship" that are negotiated.
} 
Figure A.1: The First Page of Theresa May's Article 50 Notification Letter.

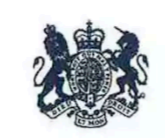

\section{DOWNING STREET \\ LONDON SW1A 2AA}

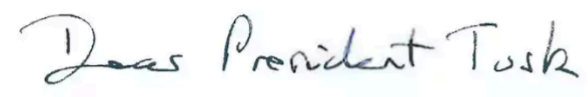

On 23 June last year, the people of the United Kingdom voted to leave the European Union. As I have said before, that decision was no rejection of the values we share as fellow Europeans. Nor was it an attempt to do harm to the European Union or any of the remaining member states. On the contrary, the United Kingdom wants the European Union to succeed and prosper. Instead, the referendum was a vote to restore, as we see it, our national self-determination. We are leaving the European Union, but we are not leaving Europe - and we want to remain committed partners and allies to our friends across the continent.

Earlier this month, the United Kingdom Parliament confirmed the result of the referendum by voting with clear and convincing majorities in both of its Houses for the European Union (Notification of Withdrawal) Bill. The Bill was passed by Parliament on 13 March and it received Royal Assent from Her Majesty The Queen and became an Act of Parliament on 16 March.

Today, therefore, I am writing to give effect to the democratic decision of the people of the United Kingdom. I hereby notify the European Council in accordance with Article 50(2) of the Treaty on European Union of the United Kingdom's intention to withdraw from the European Union. In addition, in accordance with the same Article 50(2) as applied by Article 106a of the Treaty Establishing the European Atomic Energy Community, I hereby notify the European Council of the United Kingdom's intention to withdraw from the European Atomic Energy Community. References in this letter to the European Union should therefore be taken to include a reference to the European Atomic Energy Community. 


\section{Appendix B}

Table B.1: Estimates of the Effect of Brexit Notification on Return Intentions - Students with firm migration plans.

Dependent Variable: Intention to leave the UK after graduation

\begin{tabular}{|c|c|c|c|}
\hline & (1) & $(2)$ & $(3)$ \\
\hline $\mathrm{EU} \times$ Post & $\begin{array}{r}0.010 \\
(0.047)\end{array}$ & $\begin{array}{r}0.001 \\
(0.039)\end{array}$ & $\begin{array}{r}0.021 \\
(0.038)\end{array}$ \\
\hline $\mathrm{EU}$ & $\begin{array}{l}-0.199^{* * *} \\
(0.053)\end{array}$ & $\begin{array}{l}-0.152^{* * *} \\
(0.048)\end{array}$ & $\begin{array}{l}-0.166^{* * *} \\
(0.045)\end{array}$ \\
\hline Post & $\begin{array}{c}0.039^{*} \\
(0.021)\end{array}$ & $\begin{array}{r}0.030 \\
(0.022)\end{array}$ & $\begin{array}{r}0.016 \\
(0.026)\end{array}$ \\
\hline Age & & $\begin{array}{r}0.003 \\
(0.003)\end{array}$ & $\begin{array}{r}0.003 \\
(0.003)\end{array}$ \\
\hline Female & & $\begin{array}{l}-0.065 \\
(0.076)\end{array}$ & $\begin{array}{r}-0.081 \\
(0.086)\end{array}$ \\
\hline Male & & $\begin{array}{l}-0.015 \\
(0.075)\end{array}$ & $\begin{array}{l}-0.032 \\
(0.084)\end{array}$ \\
\hline Single & & $\begin{array}{r}0.005 \\
(0.028)\end{array}$ & $\begin{array}{r}0.009 \\
(0.028)\end{array}$ \\
\hline Works whilst studying & & $\begin{array}{l}-0.146^{* * *} \\
(0.022)\end{array}$ & $\begin{array}{l}-0.158^{* * *} \\
(0.024)\end{array}$ \\
\hline Length of stay in the UK (years) & & $\begin{array}{l}-0.042^{* * *} \\
(0.007)\end{array}$ & $\begin{array}{l}-0.043^{* * *} \\
(0.006)\end{array}$ \\
\hline Undergraduate & & $\begin{array}{l}-0.216^{* * *} \\
(0.035)\end{array}$ & $\begin{array}{l}-0.227^{* * *} \\
(0.033)\end{array}$ \\
\hline Postgraduate & & $\begin{array}{l}-0.181^{* * *} \\
(0.042)\end{array}$ & $\begin{array}{l}-0.174^{* * *} \\
(0.042)\end{array}$ \\
\hline Very good health & & $\begin{array}{l}-0.044^{* *} \\
(0.017)\end{array}$ & $\begin{array}{l}-0.050^{* * *} \\
(0.017)\end{array}$ \\
\hline Mean of dep. var. & 0.63 & 0.63 & 0.63 \\
\hline$R^{2}$ & .035 & .125 & .151 \\
\hline Observations & 2,239 & 2,239 & 2,239 \\
\hline Number of clusters & 45 & 45 & 45 \\
\hline Background controls & No & Yes & Yes \\
\hline Subject FE & No & No & Yes \\
\hline University FE & No & No & Yes \\
\hline
\end{tabular}

Source.--SoGIS wave 1.

Notes. - The table reports results from difference-in-differences specifications estimated by OLS. We restrict the analysis to the subsample of students who are certain about their post-study migration intentions. Column (3) includes subject fixed effects and university fixed effects.

Robust standard errors in parentheses are clustered at the university level.

Significance levels: ${ }^{*} p<0.1,{ }^{* *} p<0.05,{ }^{* * *} p<0.01$. 
Table B.2: Balancing Tests Before the Notification of Article 50.

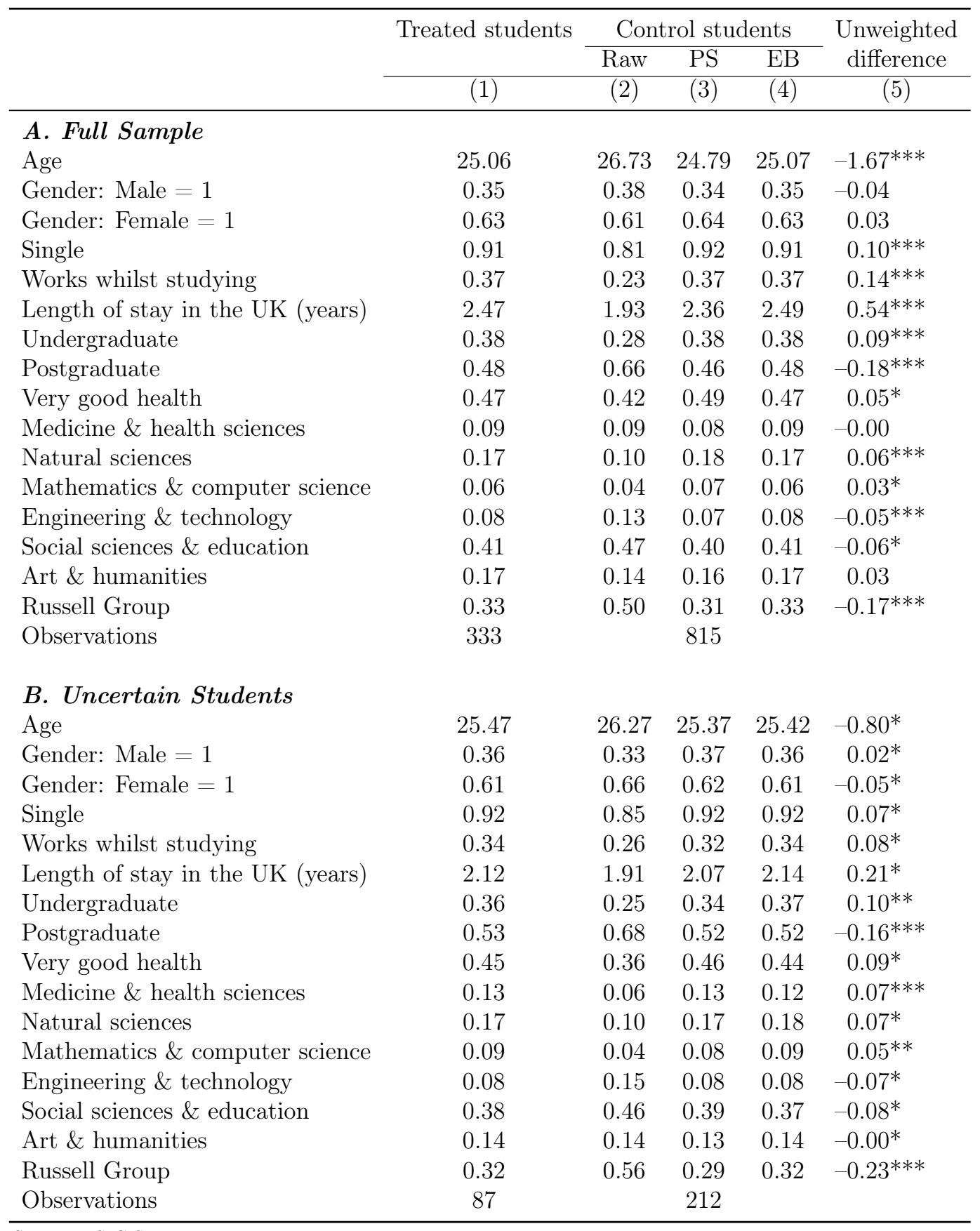

Source.- - SoGIS wave 1.

Notes. - The table reports summary statistics for the pre-A50 period. Panel A refers to all international students and Panel B refers to the subsample of students who are uncertain about their post-study migration intentions. The means of the key control variables are reported for EU students, for non-EU students before reweighting, and for non-EU students after reweighting. The control group is reweighted to match the covariate moments in the treatment group. Columns (3) and (4) report the means for the reweighted control group according to the propensity score weighting method and entropy balancing, respectively. The last column shows the difference in means between treated and control students before reweighting. The reference category of the dummy variables: "Gender: Other/missing" and "Subject of study: Combined" are excluded from balancing because of collinearity.

$* / * * / * * *$ indicate difference in means between the two groups is statistically significant at the $0.1 / 0.05 / 0.01$ level. 
Table B.3: Balancing Tests After the Notification of Article 50.

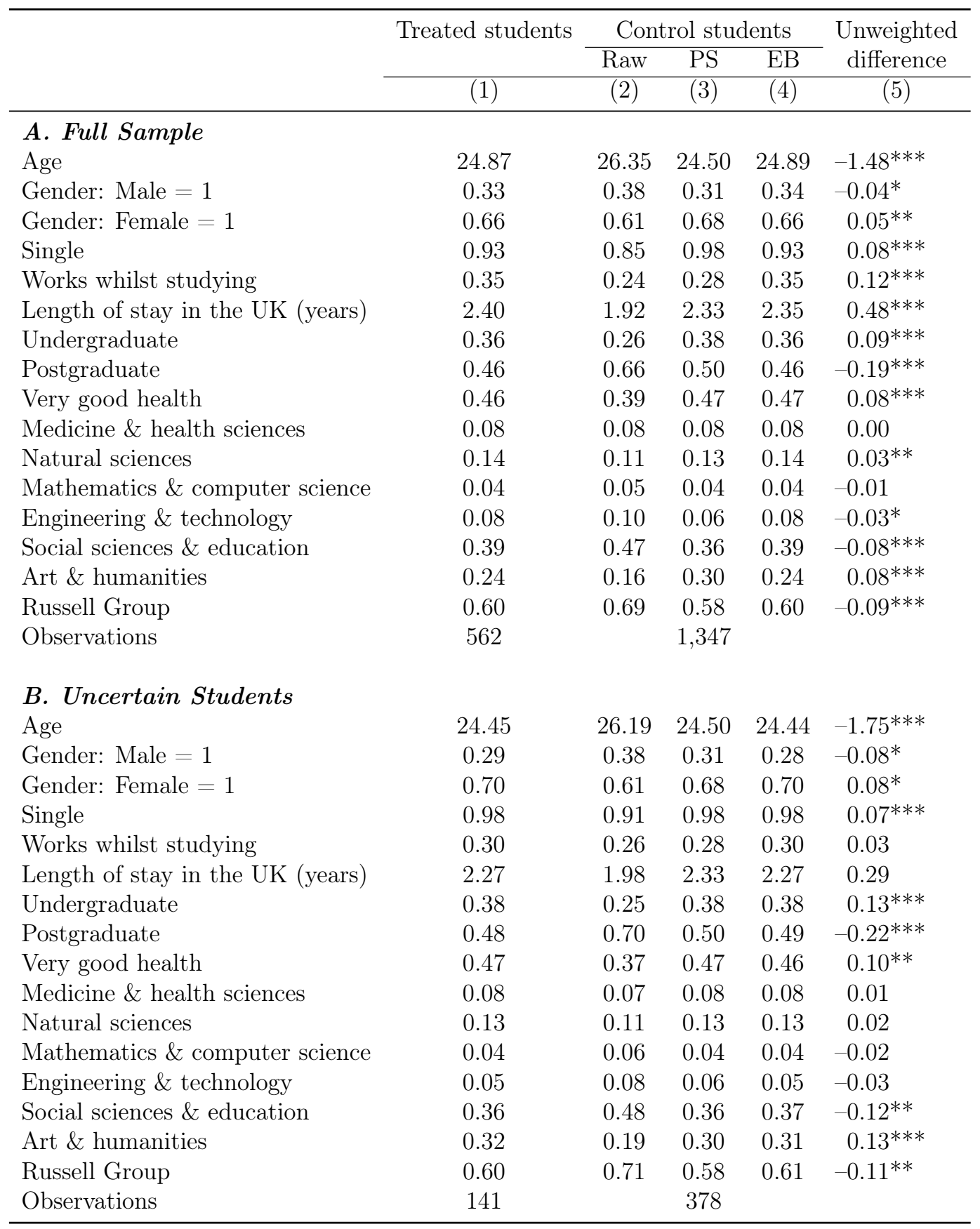

Source.--SoGIS wave 1.

Notes.- The table reports summary statistics for the post-A50 period. Panel A refers to all international students and Panel $\mathrm{B}$ refers to the subsample of students who are uncertain about their post-study migration intentions. The means of the key control variables are reported for EU students, for non-EU students before reweighting, and for non-EU students after reweighting. The control group is reweighted to match the covariate moments in the treatment group. Columns (3) and (4) report the means for the reweighted control group according to the propensity score weighting method and entropy balancing, respectively. The last column shows the difference in means between treated and control students before reweighting. The reference category of the dummy variables: "Gender: Other/missing" and "Subject of study: Combined" are excluded from balancing because of collinearity.

$* / * * / * * *$ indicate difference in means between the two groups is statistically significant at the $0.1 / 0.05 / 0.01$ level. 


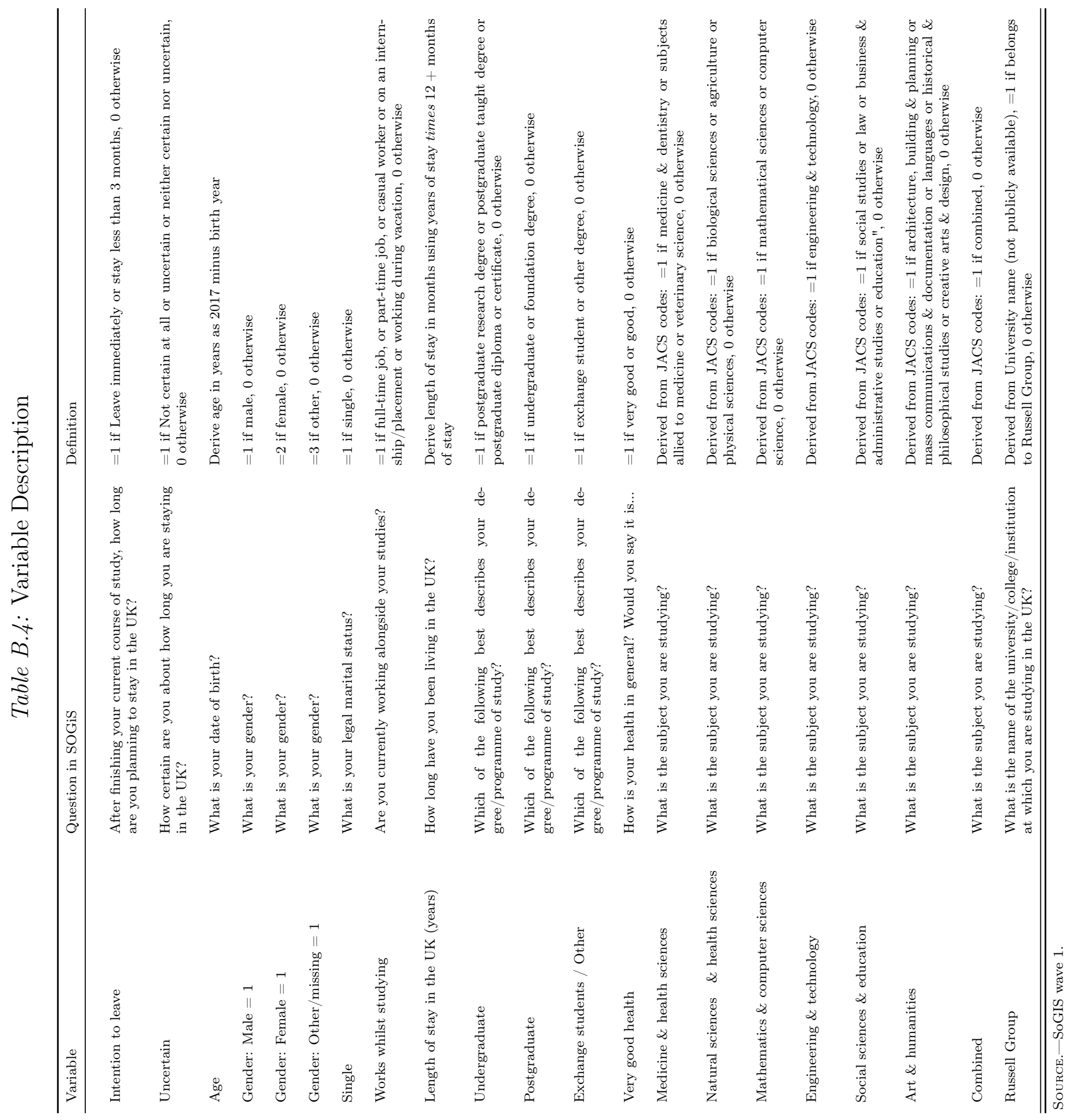

